\title{
A high resolution tidal model for the coast of Møre and Trøndelag, Mid Norway
}

\author{
H. Moe, B. Gjevik and A. Ommundsen *
}

April 27, 2000

\begin{abstract}
A numerical model with grid resolution $500 \mathrm{~m}$ has been used to simulate tides on a section of the shelf off the coast of Møre and Trøndelag in western Norway. The model spans about $3^{\circ}$ latitude and covers a sea area of approximately 8 . $10^{4} \mathrm{~km}^{2}$. The fine spatial resolution resolves the important fine scale features of the bottom topography on the shelf and the complex coastline with fjords and islands. Boundary conditions at the oceanic sides of the model domain are obtained by interpolation from a larger scale tidal model covering the Nordic Seas. The semi-diurnal components $M_{2}, S_{2}$ and $N_{2}$ and the diurnal component $K_{1}$ are simulated. Harmonic constants for sea level are compared with observations from 28 stations. The standard deviations between the observed and modelled amplitudes and phases for the dominant semi-diurnal component, $M_{2}$, are $1.7 \mathrm{~cm}$ and 5.1 degrees respectively.

Current fields from the model are compared with observations from stations along the pipeline from Tjeldbergodden on the coast to the oil and gas fields on the northern rim of Haltenbanken.
\end{abstract}

\section{Introduction}

The continental shelf outside Møre and Trøndelag on the western coast of Norway is only about $70 \mathrm{~km}$ wide west of Alesund while the width increases northward to about $230 \mathrm{~km}$ west of Rørvik (figures 1-2). Several banks are located on this section of the shelf. The largest is Haltenbanken with the central shallow part about $100 \mathrm{~km}$ southwest of Rørvik with depths of about $100 \mathrm{~m}$. Along the shelf edge a strong branch of the Norwegian Atlantic Current is flowing, Orvik and Mork (1996), Orvik et al. (1999a, 1999b) and Mathisen (1998). On the shelf the current is generally weaker with topographically trapped anticyclonic eddies over the banks, Eide (1979), Haugan et al. (1991), Gjevik and Moe (1994). Near the coast current speed is higher due to the Norwegian coastal current. These features are also clearly revealed by experiments with Lagrangian drifters, Poulain et al. (1996), Sætre (1999). The favorable circulation pattern and supply of nutrition make the banks important spawning grounds for herring, coalfish (pollock) and other commercially important fish stocks. Exploration for oil and gas started in this area at about 1985. Today several production fields

\footnotetext{
*Department of Mathematics, University of Oslo P.O.Box 1053, 0316 Blindern, Oslo, Norway
} 


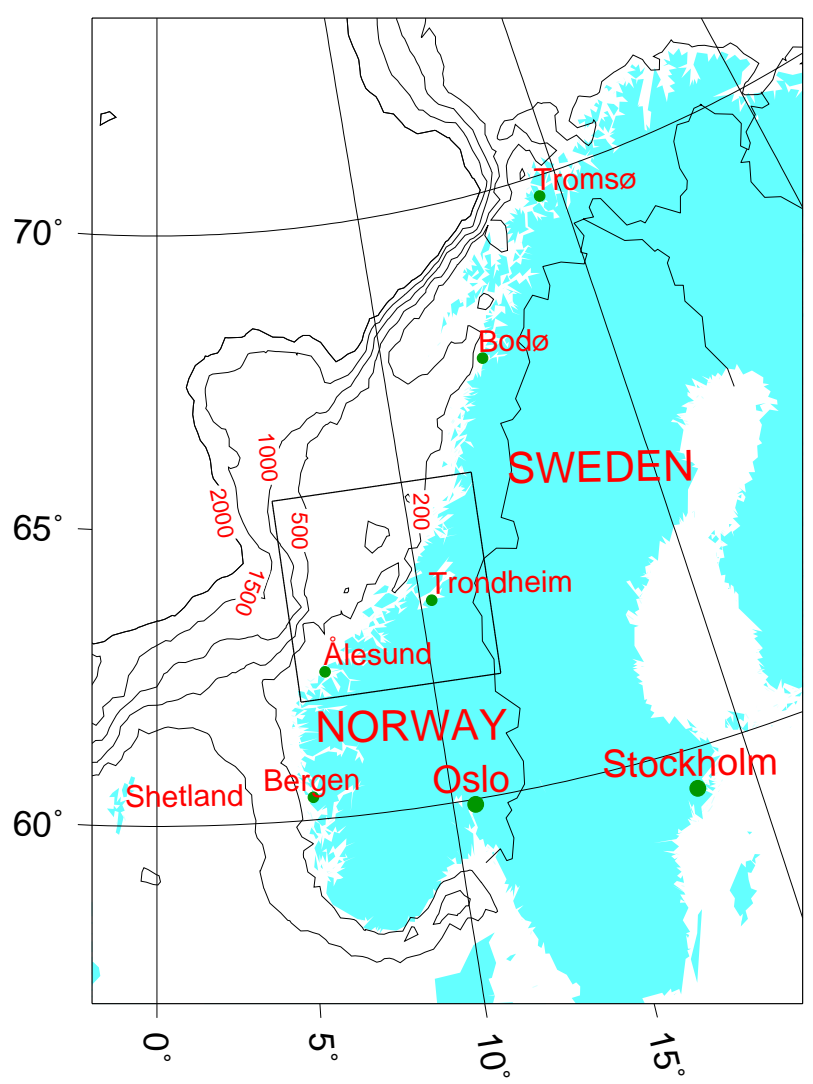

Figure 1: Map of Norwegian continental shelf with depth contours (meter) and model domain (rectangular box).

are in operation west and north of Haltenbanken, notably the Draugen (map code 6 , figure 2), Heidrun (20 km west of map code 35) and Midgard fields (near map code 7 ). Explorations have now moved into deeper water with plans for production at the fields Ormen Lange on the shelf slope west of Kristiansund and Helland Hansen (map code 36). Pipelines for oil and gas are built in the area from the Heidrun and Aasgard fields on the northern rim of Haltenbanken to the refinery plant at Tjeldbergodden (near map code 29). For these reasons there has been a considerable interest in studying current, waves and other metocean conditions in this area of the Norwegian shelf. Several field measurement programs have been conducted, mostly funded by the oil industry. Only some of the results from these studies are published in scientific journals while the main part of the results are available in project and institute reports, often difficult to obtain.

The tide is an important part of the current variability in this area, particularly in the coastal zone, and have previously been modelled with relatively coarse grid models covering the adjacent deep sea, Gjevik (1990), and a local model with refined grid resolution, Nøst (1988). Gjevik et al. (1992) implemented a high resolution model with grid size $0.5 \mathrm{~km}$ for this area for the Norwegian oil company Statoil. Results of the model simulations with comparison with sea level and current measurements along the track of the pipeline between Tjeldbergodden and Heidrun were published in the Statoil report. The station names in table 1 starting with "St" were chosen in compliance with the station names in this report. We have now extended the model area (figure 2) 


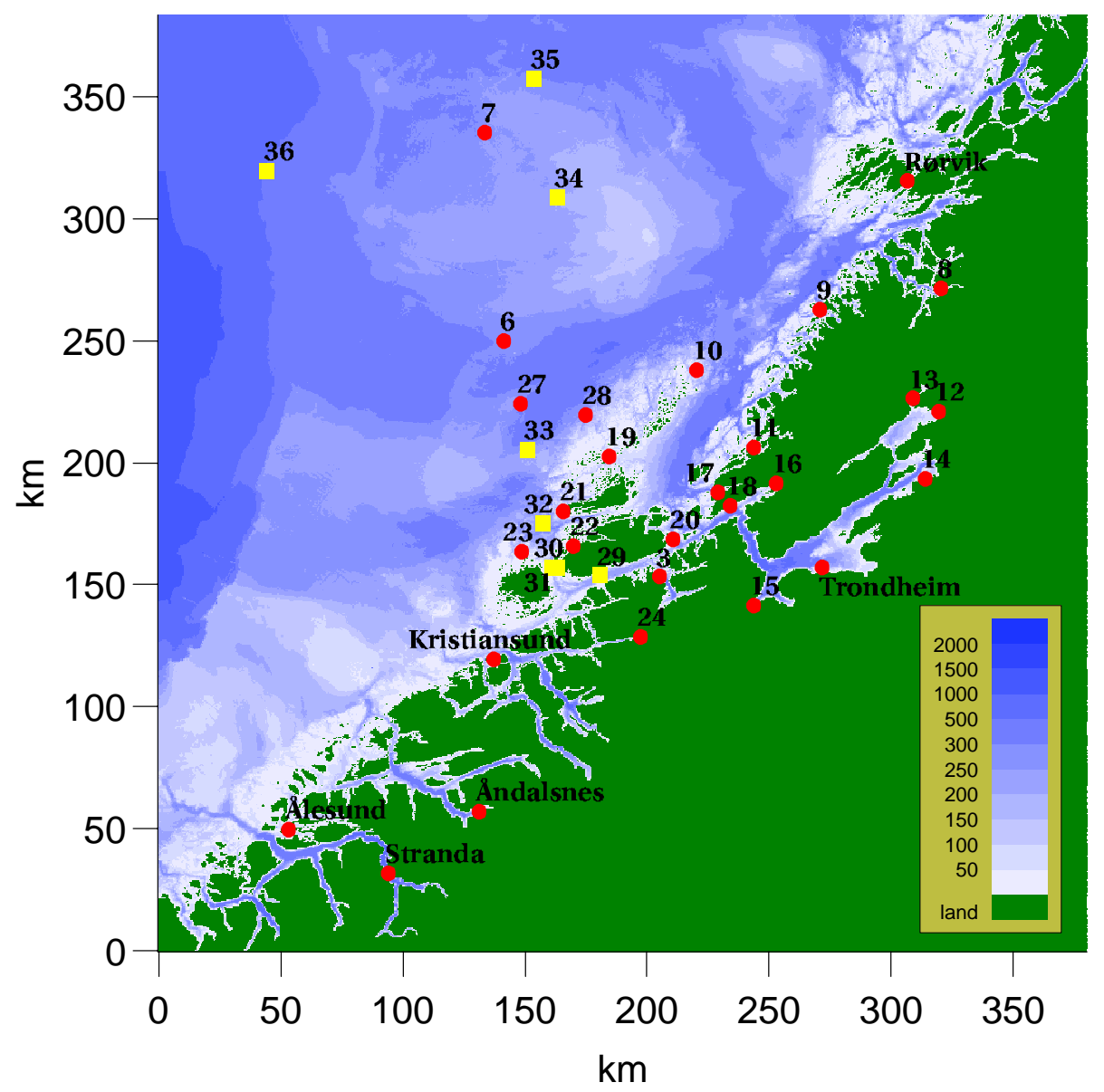

Figure 2: Model domain with $0.5 \mathrm{~km}$ grid resolution. Color depth-scale in meters. The position of the tidal stations, above gap in table 1, are marked with (red) dots and appropriate map codes. The (yellow) squares indicate stations with only current measurements (below gap line in table 1 ).

and upgraded the boundary input for this model. The new model covers about $8 \cdot 10^{4}$ $\mathrm{km}^{2}$ sea area spanning from the shelf edge to the inner fjords with a grid resolution of $0.5 \mathrm{~km}$. Both the important topographic feature of banks and trenches on the shelf and fjords and channels between islands are resolved by this model. Simulations are performed for the main semi-diurnal components $M_{2}, S_{2}$ and $N_{2}$ and the diurnal component $K_{1}$. The results are compared with sea level observations from 28 stations and current observations from 12 stations, most of them located along the track of the pipeline to Tjeldbergodden.

Three large islands are located at the coast in the center of the model domain; Hitra (near map code 20), Smøla (near map code 31) and Frøya (map code 21). A chain of small islands, Froan, stretches northeast-ward from Frøya towards Halten (map code 10). Between this chain of islands and the main land is a deep ocean bay, Frohavet, cutting inwards towards the entrance to Trondheimsfjorden. This system of islands with sounds and channels in between has an important effect on the tide in the area.

High resolution tidal modelling for shelf and coastal areas with complex bathymetry and coastline is a challenging and rapidly developing subject. A review of the state of the art is given by Davies et al. (1997a, 1997b). In particular the treatment of strong non-linear effects such as turbulence, flow separation and eddy formation is a 
difficult task which requires special precautions (Geyer 1993, Maddock and Pingree 1978). Although this model study aims specifically towards an understanding of the dynamics of the tides in the Haltenbanken area many of the problems accounted here are of wider interest.

A similar high resolution model, as used in this study, has recently been developed for the Lofoten area in northern Norway (Moe et al. 2000).

\section{Model Equations}

The depth integrated shallow water equations are formulated in flux form in a Cartesian coordinate system $(x, y, z)$ with the $\mathrm{x}$ and $\mathrm{y}$ axis in the horizontal plane and the $\mathrm{z}$ axis vertical:

$$
\begin{aligned}
& \frac{\partial U}{\partial t}+\frac{\partial}{\partial x}\left(\frac{U^{2}}{H}\right)+\frac{\partial}{\partial y}\left(\frac{U V}{H}\right)-f V=-g H \frac{\partial \eta}{\partial x}-c_{D} \frac{\sqrt{U^{2}+V^{2}}}{H} \frac{U}{H}+B_{x} \\
& \frac{\partial V}{\partial t}+\frac{\partial}{\partial x}\left(\frac{U V}{H}\right)+\frac{\partial}{\partial y}\left(\frac{V^{2}}{H}\right)+f U=-g H \frac{\partial \eta}{\partial y}-c_{D} \frac{\sqrt{U^{2}+V^{2}}}{H} \frac{V}{H}+B_{y}
\end{aligned}
$$

where $(U, V)$ are the components of volume flux vector per unit length in the horizontal plane, $\eta$ the vertical displacement of the sea surface from the mean sea level, $H=$ $H_{0}+\eta$ the total depth, $H_{0}$ the mean depth, $g$ acceleration of gravity, $f$ the Coriolis parameter, $c_{D}$ the drag coefficient of the quadratic bottom shear stress, and $\left(B_{x}, B_{y}\right)$ the components of the horizontal shear stress. In addition the continuity equation reads:

$$
\frac{\partial \eta}{\partial t}=-\frac{\partial U}{\partial x}-\frac{\partial V}{\partial y}
$$

The depth mean current velocity is defined by

$$
\bar{u}=\frac{U}{H}, \quad \bar{v}=\frac{V}{H}
$$

In this model domain the direct effect of the tide generating forces is negligible, and the tidal motion is mainly driven by the boundary input i.e. sea surface elevation and volume fluxes. In the present problem these equations span a wide parameter range from weak tidal flows on the deeper part of the shelf to strong tidal currents at the coast. We introduce a velocity scale $u_{s}$, a time scale $t_{s}$ corresponding to half the tidal period, a tidal amplitude $a$, a length scale for the spatial variation of the tidal flow $l_{s}$ and a depth scale $h_{s}$. With this scaling we can define the tidal excursion $l_{t}=u_{s} t_{s}$ and the equations (1)-(2) can be recast into dimensionless form:

$$
\begin{aligned}
& \frac{\partial U}{\partial t}+\alpha\left[\frac{\partial}{\partial x}\left(\frac{U^{2}}{H}\right)+\frac{\partial}{\partial y}\left(\frac{U V}{H}\right)\right]-\delta V=-\beta H \frac{\partial \eta}{\partial x}-\gamma \frac{\sqrt{U^{2}+V^{2}}}{H} \frac{U}{H} \\
& \frac{\partial V}{\partial t}+\alpha\left[\frac{\partial}{\partial x}\left(\frac{U V}{H}\right)+\frac{\partial}{\partial y}\left(\frac{V^{2}}{H}\right)\right]+\delta U=-\beta H \frac{\partial \eta}{\partial y}-\gamma \frac{\sqrt{U^{2}+V^{2}}}{H} \frac{V}{H}
\end{aligned}
$$


with $B_{x}=B_{y}=0$. The dimensionless form of the continuity equation reads:

$$
\frac{\epsilon}{\alpha} \frac{\partial \eta}{\partial t}=-\frac{\partial U}{\partial x}-\frac{\partial V}{\partial y}
$$

with $H=H_{0}+\epsilon \eta$. The same symbols are here tacitly used for dimensionless variables $U, V, H$ and $\eta$ as in the dimensional equations (1)-(3). The dimensionless parameters are defined by:

$$
\alpha=\frac{l_{t}}{l_{s}}, \quad \beta=\frac{g a}{u_{s}^{2}} \frac{l_{t}}{l_{s}}, \gamma=\frac{c_{D} l_{t}}{h_{s}}, \quad \delta=f t_{s}, \quad \epsilon=\frac{a}{h_{s}}
$$

Here $\alpha$, and $\epsilon$ are measures of the importance of the convective terms and the nonlinear surface elevation terms respectively. The parameters $\beta, \gamma$, and $\delta$ scale pressure, bottom friction and rotational effects respectively. In deep water $\alpha, \epsilon$ and $\gamma \ll 1$ reducing the equations to the linearized shallow water equation with negligible bottom friction. Near the coast, with strong tidal currents, $\alpha, \beta, \gamma$ are of $O(1)$ and all terms in the equation of motion have to be retained. In not too shallow water $\epsilon \ll 1$ the left hand side of equation (3) may be neglected rendering a nearly non-divergent volume flux as long as $\alpha$ is of $O(1)$.

In this paper we have tested the performance of a linear tidal model and made the approximations $\alpha=\epsilon=0$ and $\epsilon / \alpha$ of $O(1)$. The equations are then discretized on a C-grid, Mesinger and Arakawa (1976), with a semi-implicit numerical scheme. This scheme is widely used for depth integrated ocean models. A discussion of its dispersion and stability properties is given e.g. by Martinsen et al. (1979) and Gjevik and Straume (1989).

The stability criteria expressed by the numerical time step, $\Delta t$, is:

$$
\Delta t \leq \frac{\Delta x}{2 \sqrt{2 g H_{\max }}}
$$

where $\Delta x$ is the grid size and $H_{\max }$ is the maximum depth in the model domain.

\section{Model set up and boundary conditions}

The depth matrix was evaluated on an UTM coordinate grid with $\Delta x=0.5 \mathrm{~km}$ resolution. Near the coast average depths for each grid cell were read from Norwegian coastal charts with scale $1: 50000$. Outside the zone covered by the coastal charts depths are from a bathymetric data base with $500 \mathrm{~m}$ spatial resolution, Norwegian Hydrographic Service (1992). The resulting depth matrix of $761 \times 767$ grid points is depicted in figure 2.

Boundary conditions for the model were obtained by interpolating surface elevation and volume fluxes from a larger scale model of the Norwegian and the Barents Sea with $25 \mathrm{~km}$ grid resolution, Gjevik et al. (1990, 1994). We used the flow relaxation scheme (FRS), Martinsen and Engedahl (1987), to impose the boundary conditions. The rationale behind this scheme is to soften the transition from an exterior solution (here the interpolated data) to an interior solution (model area) by use of a grid zone where the two solutions dominate at each ends respectively. The width of the zone is here taken to be ten grid cells. 
We have used just surface elevation and both surface and volume flux as the exterior solution for single or selected combinations of the tidal components $M_{2}, S_{2}, N_{2}$ and $K_{1}$. The exterior solution is gradually increased from a state of rest at simulation start $(t=0)$ determined by the factor $(1-\exp (\sigma t))$. We have used $\sigma=4.6 \cdot 10^{-5} s^{-1}$ implying full effect of the exterior solution after about 12 hours. The simulation times are taken to be 192 hours for the semi-diurnal components and 240 hours for the diurnal component. Entire fields (all grid points) for current and elevation are stored for one tidal period at one hour intervals for each component at the end of the simulations, while we for 45 stations within the model area records are kept with three minutes sampling for the whole simulation interval. The time series for the stations have been used to ensure that a steady state oscillation is reached. Harmonic analysis is performed on the full fields and on the time series of the stations yielding amplitude and phase.

We have made most of the simulations including bottom friction (coefficient $c_{D}=$ 0.003), however we also provide results from runs without friction for comparison. Figures based on the fields are taken from the simulations without friction and with just surface elevation as the exterior solution.

Table 1: List of stations.

\begin{tabular}{|c|c|c|}
\hline Station & Coordinates & Map Code \\
\hline Rørvik & $64^{\circ} 52^{\prime} N, 11^{\circ} 15^{\prime} E$ & $\overline{\overline{\text { Rørvik (1) }}}$ \\
\hline Trondheim & $63^{\circ} 26^{\prime} N, 10^{\circ} 26^{\prime} E$ & Trondheim (2) \\
\hline Heimsjøen & $63^{\circ} 26^{\prime} N, 09^{\circ} 07^{\prime} E$ & 3 \\
\hline Kristiansund & $63^{\circ} 07^{\prime} N, 07^{\circ} 45^{\prime} E$ & Kristiansund (4) \\
\hline Alesund & $62^{\circ} 28^{\prime} N, 06^{\circ} 09^{\prime} E$ & Alesund (5) \\
\hline Draugen & $64^{\circ} 17^{\prime} N, 07^{\circ} 47^{\prime} E$ & 6 \\
\hline Haltenbanken 1 & $65^{\circ} 03^{\prime} N, 07^{\circ} 35^{\prime} E$ & 7 \\
\hline Namsos & $64^{\circ} 28^{\prime} N, 11^{\circ} 30^{\prime} E$ & 8 \\
\hline Buholmråsa & $64^{\circ} 24^{\prime} N, 10^{\circ} 28^{\prime} E$ & 9 \\
\hline Halten Fyr & $64^{\circ} 11^{\prime} N, 09^{\circ} 25^{\prime} E$ & 10 \\
\hline Lysøysundet & $63^{\circ} 53^{\prime} N, 09^{\circ} 52^{\prime} E$ & 11 \\
\hline Steinkjer & $64^{\circ} 02^{\prime} N, 11^{\circ} 30^{\prime} E$ & 12 \\
\hline Malm & $64^{\circ} 05^{\prime} N, 11^{\circ} 14^{\prime} E$ & 13 \\
\hline Levanger & $63^{\circ} 45^{\prime} N, 11^{\circ} 18^{\prime} E$ & 14 \\
\hline Orkanger & $63^{\circ} 19^{\prime} N, 09^{\circ} 52^{\prime} E$ & 15 \\
\hline Råkvåg & $63^{\circ} 46^{\prime} N, 10^{\circ} 04^{\prime} E$ & 16 \\
\hline Uthaug & $63^{\circ} 44^{\prime} N, 09^{\circ} 35^{\prime} E$ & 17 \\
\hline Brekstad & $63^{\circ} 41^{\prime} N, 09^{\circ} 40^{\prime} E$ & 18 \\
\hline Mausundvær & $63^{\circ} 52^{\prime} N, 08^{\circ} 40^{\prime} E$ & 19 \\
\hline Hestvika & $63^{\circ} 34^{\prime} N, 09^{\circ} 12^{\prime} E$ & 20 \\
\hline Titran & $63^{\circ} 40^{\prime} N, 08^{\circ} 19^{\prime} E$ & 21 \\
\hline Kvenvær & $63^{\circ} 32^{\prime} N, 08^{\circ} 23^{\prime} E$ & 22 \\
\hline Veidholm & $63^{\circ} 31^{\prime} N, 07^{\circ} 58^{\prime} E$ & 23 \\
\hline Vinjeøra & $63^{\circ} 13^{\prime} N, 08^{\circ} 59^{\prime} E$ & 24 \\
\hline Ândalsnes & $62^{\circ} 33^{\prime} N, 07^{\circ} 40^{\prime} E$ & Andalsnes (25) \\
\hline Stranda & $62^{\circ} 19^{\prime} N, 06^{\circ} 57^{\prime} E$ & Stranda (26) \\
\hline St15 & $64^{\circ} 04^{\prime} N, 07^{\circ} 57^{\prime} E$ & 27 \\
\hline St16 & $64^{\circ} 39^{\prime} N, 07^{\circ} 43^{\prime} E$ & 28 \\
\hline 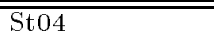 & $63^{\circ} 26^{\prime} N, 08^{\circ} 37^{\prime} E$ & 29 \\
\hline St07 & $63^{\circ} 27^{\prime} N, 08^{\circ} 13^{\prime} E$ & 30 \\
\hline St09 & $63^{\circ} 32^{\prime} N, 08^{\circ} 15^{\prime} E$ & 31 \\
\hline St11 & $63^{\circ} 37^{\prime} N, 08^{\circ} 08^{\prime} E$ & 32 \\
\hline St13 & $63^{\circ} 53^{\prime} N, 08^{\circ} 00^{\prime} E$ & 33 \\
\hline Haltenbanken 2 & $64^{\circ} 49^{\prime} N, 08^{\circ} 13^{\prime} E$ & 34 \\
\hline Haltenbanken 3 & $65^{\circ} 15^{\prime} N, 08^{\circ} 00^{\prime} E$ & 35 \\
\hline Helland Hansen & $64^{\circ} 53^{\prime} N, 05^{\circ} 43^{\prime} E$ & 36 \\
\hline
\end{tabular}




\section{Results}

The calculated harmonic constants for sea level amplitude $h_{n}$ and phase relative Greenwich $g_{n}$ are compared with observations from 28 tidal stations (above the gap in table 1). For Rørvik, Trondheim, Heimsjøen, Kristiansund and Alesund (primary stations) the harmonic constants are calculated from long time series of observed sea level, Norwegian Hydrographic Service (2000). For the other tidal stations in table 1, except from Buholmråsa, Kvenvær and Vinjeøra, the harmonic constants for $M_{2}, S_{2}$ and $K_{1}$ are calculated from shorter time series, typically 2-4 weeks. For $N_{2}$ only a few stations have these short time series. We have got access to this data, which previously has not been used for validation of tidal models, from The Norwegian Hydrographic Service (NHS). For some of the stations (called secondary stations) NHS has also calculated correction factors for amplitude and time of high and low water relative to the nearest primary station. By using these correction factors we have also deduced a set of derived harmonic constants for the secondary stations. Harmonic constants for both primary and secondary stations as well as model estimates are listed in tables 2-5. Observed phases at the station Haltenbanken 1 (map code 7) are somewhat odd. They deviate from 30 to 52 degrees from model for the semi-diurnal components (from one to almost two hours of the periods) and 26 degrees for the diurnal components (almost two hours of the period). Compared to the good agreement between modelled and observed phases of other neighbouring stations we do believe that the timing or the processing of the data from this station is erroneous. This should be kept in mind when looking at the regression plots in figures $4,6,8$ and 10 .

Current data from the model is compared with observational data along the Tjeldbergodden pipeline, provided by Statoil and Oceanor. Where measurements from several depths were available we have used the mean value for comparison. For near bottom measurements we have assumed a boundary layer profile to calculate a representative mean value. More on this later in this section. All current vector plots are made with reduced resolution (every third grid point) to avoid cluttering and with no vectors drawn for depths less than 10 meters to improve readability.

\subsection{Sea level, semi-diurnal and diurnal components}

\subsubsection{The $M_{2}$ component}

Contour lines for the $M_{2}$ sea level amplitude and phase are depicted in figure 3 . The phase lines are approximately perpendicular to the shelf edge with gradually increasing phases north-northeast ward, showing that the $M_{2}$ wave component propagates basically in a north-northeasterly direction. The separation between phase lines is larger in the south part of the model area, where the shelf is narrow, which imply a larger propagation speed than in north where the shelf is wider.

By comparing amplitudes and phases with observations, table 2 and figure 4 , the best fit is found for the run with prescribed surface elevation at the open boundaries with a standard deviation of $1.7 \mathrm{~cm}$ for amplitude and 9.3 degrees for phase (5.1 degrees if station Haltenbanken 1 is excluded). The difference between the three model simulation in table 2 is however not substantial even though including flux generally gives a higher amplitude.

Inward the Trondheimsfjord (the fjord named after the city Trondheim) we see a 
increase in amplitude in good agreement with measurements, table 2.

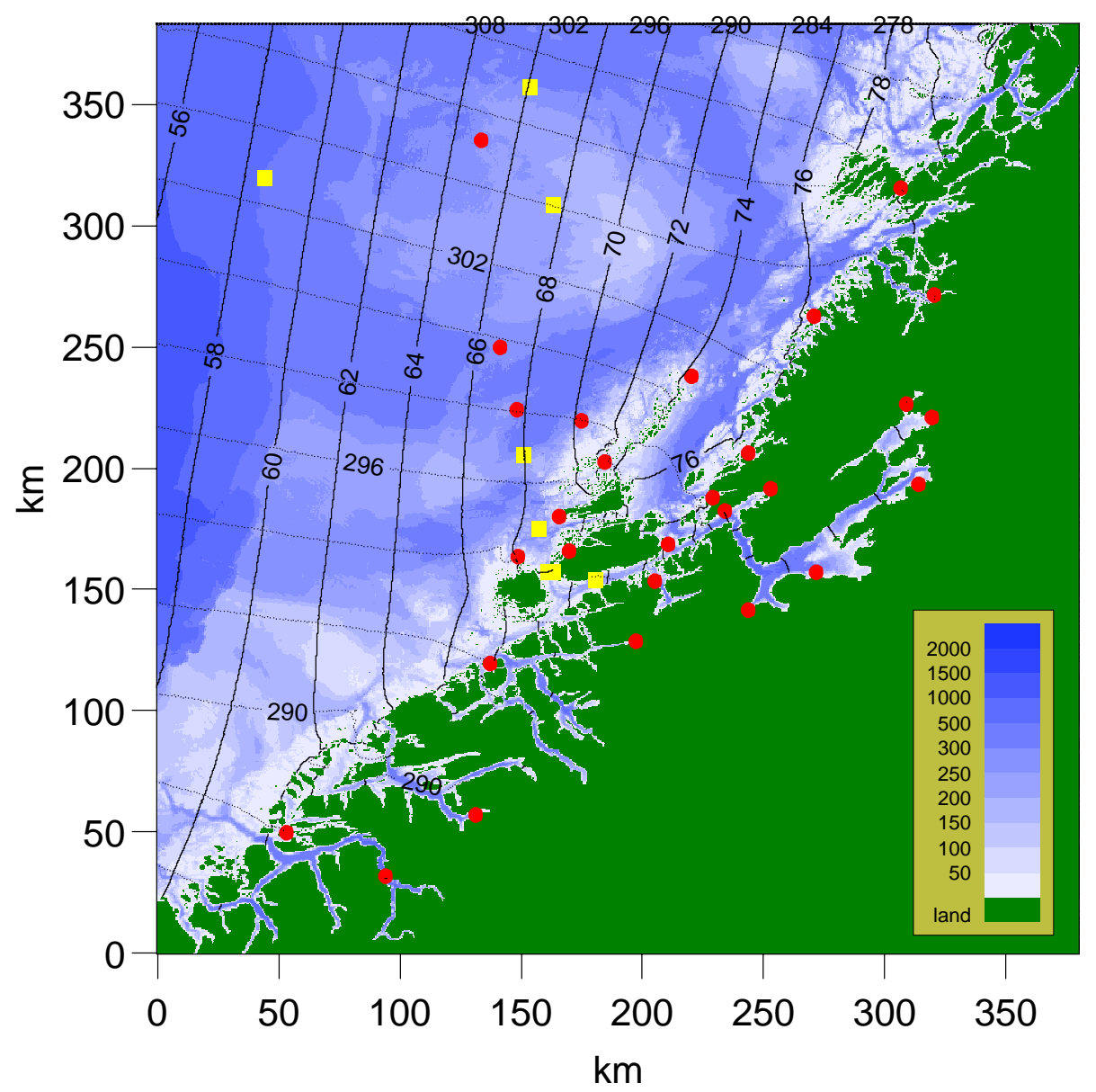

Figure 3: $M_{2}$ sea surface elevation. Isolines for amplitude (solid lines, 2-cm separation) and phase (broken lines, 2-degree separation). Shading shows depth with scale in legend (meter). Stations are marked as in figure 2.

\subsubsection{The $S_{2}$ component}

The amplitude of the $S_{2}$ component is about one third of the $M_{2}$ and the general features of the variation of the amplitude and phase are similar (figure 5). The standard deviations between modelled and observed amplitude and phase are $1.6 \mathrm{~cm}$ and 7.1 degrees respectively for the $S_{2}$ simulations with surface elevation prescribed at the open boundary as shown in table 3 and figure 6 .

\subsubsection{The $N_{2}$ component}

The amplitude of the $N_{2}$ component is about one fifth of the $M_{2}$ and the general features of the variation of the amplitude and phase are similar (figure 7 ). The standard deviations between modelled and observed amplitude and phase are $1.8 \mathrm{~cm}$ and 18.3 degrees respectively for the $N_{2}$ simulations with surface elevation prescribed at the open boundary as shown in table 4 and figure 8 .

For $N_{2}$ only ten stations are used the regression analysis. This probably explains the large standard deviations between observations and model for this component. 
Table 2: Harmonic constants for sea level $\left(M_{2}\right)$. Elevation $\left(h_{n}\right)$ is given in $\mathrm{cm}$, phase GMT $\left(g_{n}\right)$ in degrees. Measured and derived results in columns 2-5. Model results with just elevation, and both flux and elevation as exterior solution in columns 6-9. The latter also without bottom friction in columns 10-11.

\begin{tabular}{|c|c|c|c|c|c|c|c|c|c|c|}
\hline \multirow[t]{2}{*}{ Station } & \multicolumn{2}{|c|}{ Observed } & \multicolumn{2}{|c|}{ Derived } & \multicolumn{2}{|c|}{ Elevation } & \multicolumn{2}{|c|}{$\begin{array}{l}\text { Elevation } \\
\text { E Flux }\end{array}$} & \multicolumn{2}{|c|}{$\begin{array}{l}\text { Without } \\
\text { Friction }\end{array}$} \\
\hline & $h_{n}$ & $g_{n}$ & $h_{n}$ & $g_{n}$ & $h_{n}$ & $g_{n}$ & $h_{n}$ & $g_{n}$ & $h_{n}$ & $\overline{g_{n}}$ \\
\hline Rørvik & 78.8 & 309 & & & 78.8 & 306 & 79.6 & 307 & 79.6 & 307 \\
\hline Trondheim & 92.3 & 306 & & & 90.9 & 299 & 92.7 & 300 & 92.5 & 300 \\
\hline Heimsjøen & 77.8 & 301 & & & 77.1 & 297 & 78.7 & 298 & 78.7 & 297 \\
\hline Kristiansund & 67.7 & 295 & & & 68.2 & 292 & 69.9 & 293 & 69.9 & 293 \\
\hline Alesund & 61.8 & 290 & & & 62.6 & 288 & 65.3 & 289 & 65.3 & 289 \\
\hline Draugen & 67.3 & 304 & & & 67.0 & 300 & 68.3 & 300 & 68.2 & 300 \\
\hline Haltenbanken 1 & 67.7 & 344 & & & 65.1 & 305 & 66.0 & 306 & 66.0 & 306 \\
\hline Namsos & 75.9 & 306 & 77.2 & 304 & 78.9 & 304 & 80.2 & 305 & 80.2 & 305 \\
\hline Buholmråsa & & & 78.0 & 302 & 76.4 & 303 & 77.7 & 304 & 77.8 & 304 \\
\hline Halten Fyr & 74.8 & 303 & 75.6 & 306 & 74.4 & 301 & 75.8 & 302 & 75.6 & 302 \\
\hline Lysøysundet & 76.6 & 307 & 77.2 & 305 & 76.4 & 301 & 77.9 & 302 & 77.9 & 302 \\
\hline Steinkjer & 96.9 & 307 & 101.5 & 305 & 98.8 & 300 & 100.7 & 301 & 100.4 & 300 \\
\hline Malm & 97.1 & 306 & 105.2 & 305 & 99.2 & 300 & 101.2 & 301 & 100.9 & 300 \\
\hline Levanger & 98.0 & 309 & 98.8 & 311 & 95.2 & 300 & 97.1 & 301 & 96.8 & 300 \\
\hline Orkanger & 87.4 & 306 & 94.1 & 308 & 89.9 & 300 & 91.7 & 300 & 91.4 & 300 \\
\hline Råkvåg & 86.3 & 302 & 86.8 & 297 & 85.3 & 300 & 87.0 & 301 & 86.8 & 300 \\
\hline Uthaug & 76.7 & 305 & 76.5 & 300 & 77.6 & 300 & 79.0 & 301 & 79.1 & 301 \\
\hline Brekstad & 82.9 & 307 & 86.7 & 307 & 84.4 & 300 & 86.1 & 301 & 85.9 & 300 \\
\hline Mausundvær & 73.2 & 305 & 73.8 & 295 & 73.2 & 298 & 74.7 & 299 & 74.9 & 298 \\
\hline Hestvika & 77.7 & 307 & 79.9 & 305 & 78.7 & 299 & 80.2 & 300 & 80.3 & 299 \\
\hline Titran & 69.7 & 292 & 68.4 & 293 & 69.0 & 296 & 70.5 & 296 & 70.5 & 296 \\
\hline Kvenvær & & & 68.4 & 296 & 69.7 & 295 & 71.2 & 296 & 71.2 & 296 \\
\hline Veidholm & 67.4 & 297 & 69.1 & 291 & 68.8 & 294 & 70.3 & 295 & 70.4 & 295 \\
\hline Vinjeøra & & & 74.5 & 292 & 71.8 & 293 & 73.5 & 294 & 73.4 & 294 \\
\hline Andalsnes & 65.6 & 290 & 65.7 & 286 & 67.4 & 290 & 69.9 & 291 & 69.7 & 291 \\
\hline Stranda & 62.5 & 293 & 62.3 & 284 & 64.1 & 288 & 66.9 & 289 & 67.0 & 289 \\
\hline St15 & 68.3 & 300 & & & 67.9 & 298 & 69.3 & 299 & 69.2 & 299 \\
\hline St16 & 66.5 & 304 & & & 70.5 & 298 & 71.9 & 299 & 71.9 & 299 \\
\hline
\end{tabular}
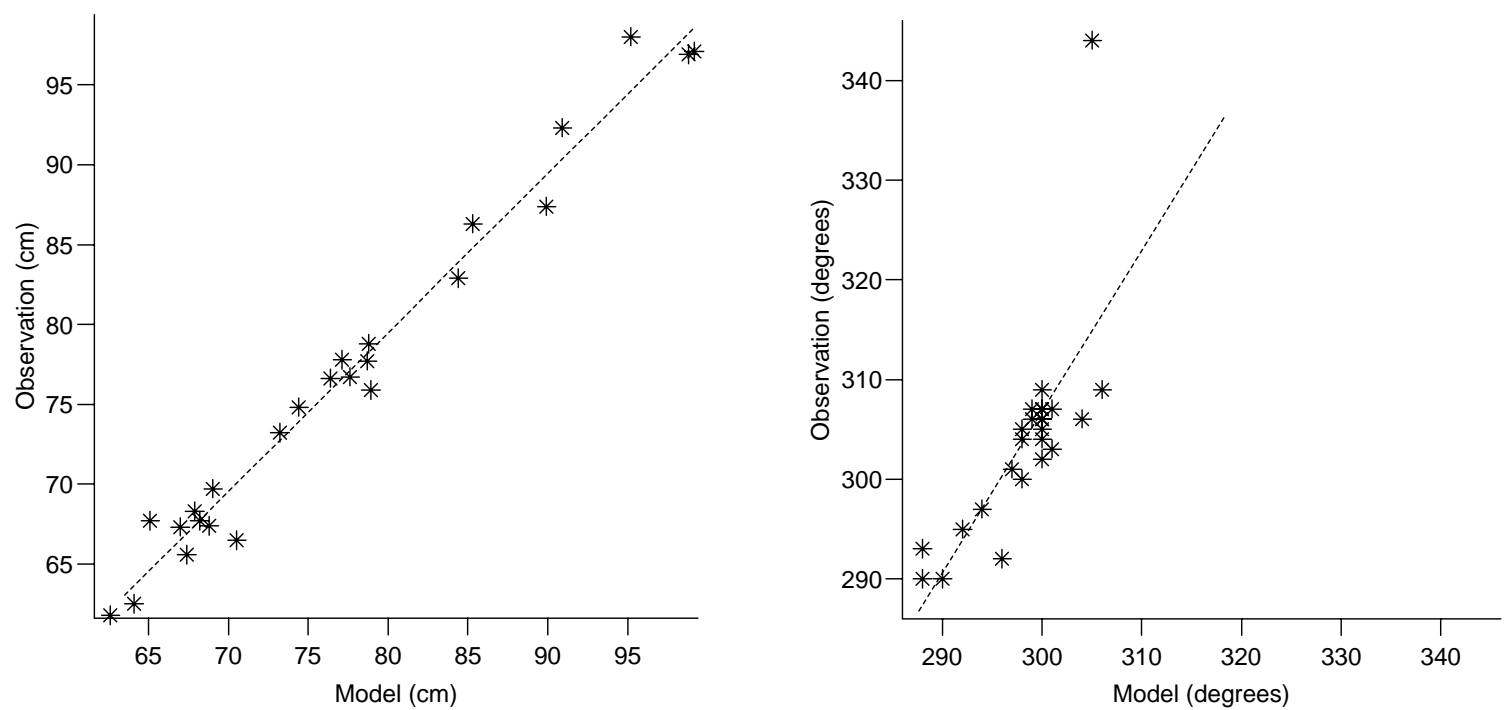

Figure 4: Scattering diagrams for $M_{2}$. Comparison between modelled and observed amplitude (left panel) and phase (right panel), for the elevation run. The least squares regression line (dashed). The standard deviation estimate between model and observation is $1.7 \mathrm{~cm}$ (amplitude) and 9.3 degrees (phase). 


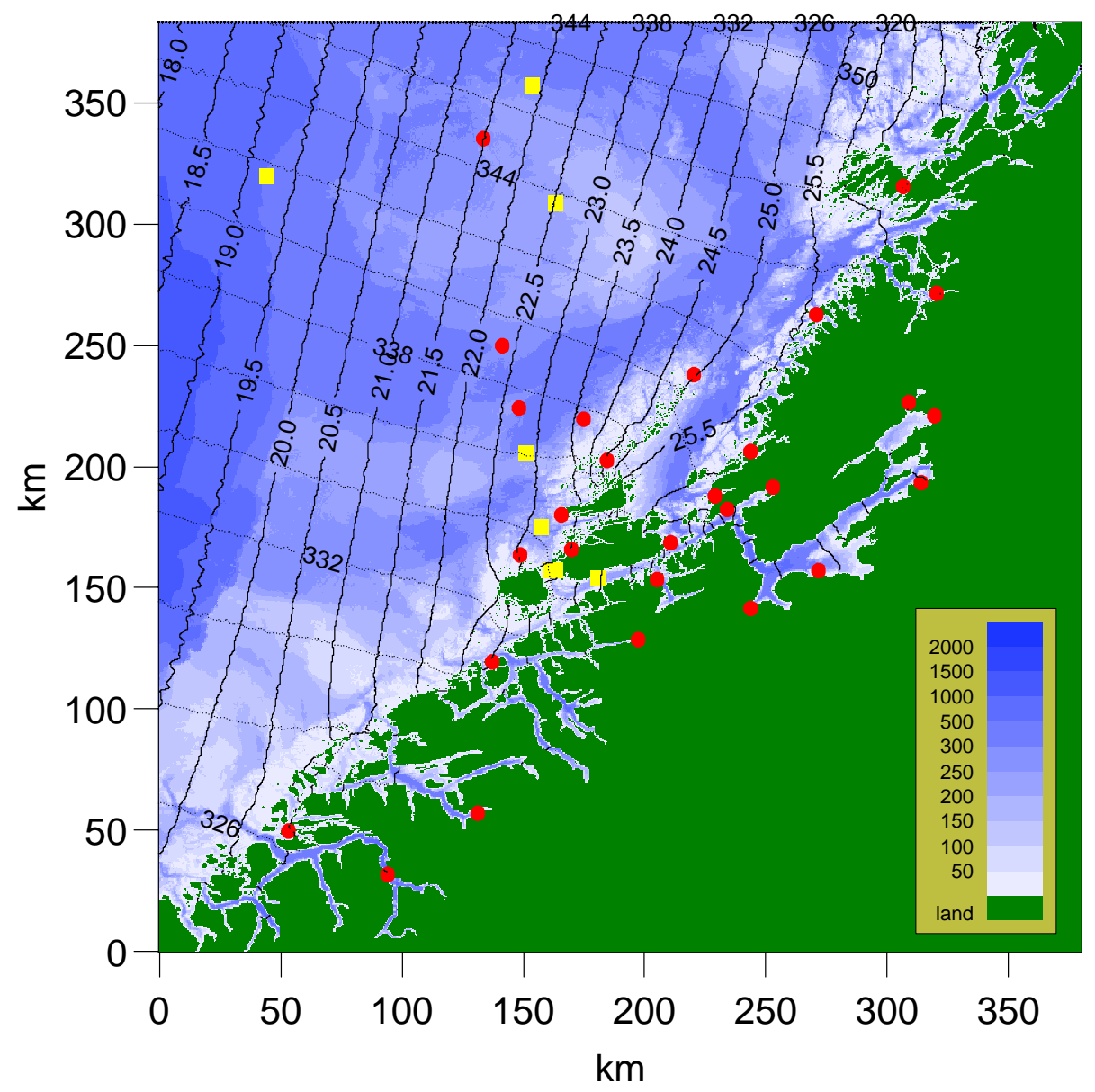

Figure 5: $S_{2}$ sea surface elevation. Isolines for amplitude (solid lines, 0.5-cm separation) and phase (broken lines, 2-degree separation). Shading shows depth with scale in legend (meter). Stations are marked as in figure 2.
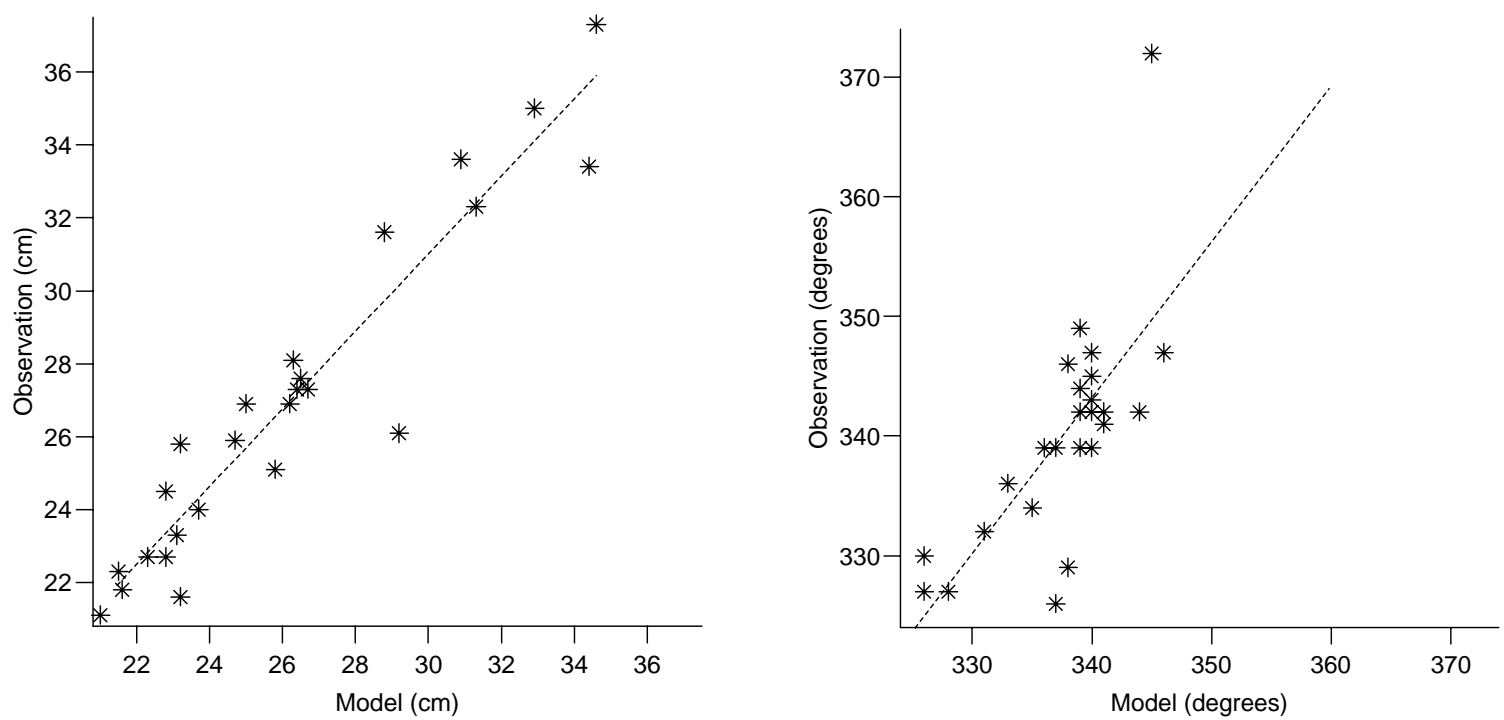

Figure 6: Scattering diagrams for $S_{2}$. Comparison between modelled and observed amplitude (left panel) and phase (right panel), for the elevation run. The least squares regression line (dashed). The standard deviation estimate between model and observation is $1.6 \mathrm{~cm}$ (amplitude) and 7.1 degrees (phase). 
Table 3: Harmonic constants for sea level $\left(S_{2}\right)$. Elevation $\left(h_{n}\right)$ is given in $\mathrm{cm}$, phase GMT $\left(g_{n}\right)$ in degrees. Measured and derived results in columns 2-5. Model results with just elevation, and both flux and elevation as exterior solution in columns 6-9. The latter also without bottom friction in columns 10-11.

\begin{tabular}{|c|c|c|c|c|c|c|c|c|c|c|}
\hline \multirow[t]{2}{*}{ Station } & \multicolumn{2}{|c|}{ Observed } & \multicolumn{2}{|c|}{ Derived } & \multicolumn{2}{|c|}{ Elevation } & \multicolumn{2}{|c|}{$\begin{array}{l}\text { Elevation } \\
\text { E Flux }\end{array}$} & \multicolumn{2}{|c|}{$\begin{array}{l}\text { Without } \\
\text { Friction }\end{array}$} \\
\hline & $h_{n}$ & $g_{n}$ & $h_{n}$ & $g_{n}$ & $h_{n}$ & $g_{n}$ & $h_{n}$ & $g_{n}$ & $h_{n}$ & $g_{n}$ \\
\hline Rørvik & 27.3 & 347 & & & 26.4 & 346 & 26.9 & 348 & 26.9 & 348 \\
\hline Trondheim & 32.3 & 344 & & & 31.3 & 339 & 31.8 & 340 & 31.8 & 339 \\
\hline Heimsjøen & 26.9 & 339 & & & 26.2 & 336 & 26.7 & 337 & 26.7 & 337 \\
\hline Kristiansund & 23.3 & 332 & & & 23.1 & 331 & 23.6 & 332 & 23.6 & 332 \\
\hline Alesund & 21.1 & 327 & & & 21.0 & 326 & 22.2 & 328 & 22.2 & 328 \\
\hline Draugen & 22.7 & 339 & & & 22.3 & 339 & 22.9 & 340 & 22.9 & 340 \\
\hline Haltenbanken 1 & 22.3 & 12 & & & 21.5 & 345 & 21.9 & 345 & 21.9 & 345 \\
\hline Namsos & 27.6 & 342 & 26.8 & 342 & 26.5 & 344 & 27.1 & 345 & 27.1 & 345 \\
\hline Buholmråsa & & & 27.0 & 340 & 25.6 & 343 & 26.2 & 344 & 26.2 & 344 \\
\hline Halten Fyr & 26.9 & 342 & 26.2 & 344 & 25.0 & 341 & 25.5 & 342 & 25.5 & 341 \\
\hline Lysøysundet & 25.1 & 341 & 26.8 & 343 & 25.8 & 341 & 26.3 & 342 & 26.3 & 342 \\
\hline Steinkjer & 33.4 & 343 & 35.5 & 343 & 34.4 & 340 & 34.8 & 340 & 34.8 & 340 \\
\hline Malm & 37.3 & 339 & 36.8 & 343 & 34.6 & 340 & 34.9 & 340 & 34.9 & 340 \\
\hline Levanger & 35.0 & 342 & 34.6 & 349 & 32.9 & 339 & 33.4 & 340 & 33.4 & 340 \\
\hline Orkanger & 33.6 & 349 & 32.9 & 346 & 30.9 & 339 & 31.4 & 340 & 31.4 & 339 \\
\hline Ràkvåg & 26.1 & 342 & 30.4 & 335 & 29.2 & 340 & 29.7 & 340 & 29.7 & 340 \\
\hline Uthaug & 28.1 & 345 & 26.3 & 337 & 26.3 & 340 & 26.8 & 341 & 26.8 & 341 \\
\hline Brekstad & 31.6 & 347 & 29.8 & 344 & 28.8 & 340 & 29.3 & 340 & 29.3 & 340 \\
\hline Mausundvær & 25.9 & 339 & 25.4 & 332 & 24.7 & 337 & 25.2 & 338 & 25.2 & 338 \\
\hline Hestvika & 27.3 & 346 & 27.5 & 342 & 26.7 & 338 & 27.2 & 339 & 27.3 & 339 \\
\hline Titran & 21.6 & 334 & 23.5 & 330 & 23.2 & 335 & 23.8 & 336 & 23.8 & 336 \\
\hline Kvenvær & & & 23.5 & 333 & 23.5 & 334 & 24.1 & 335 & 24.1 & 335 \\
\hline Veidholm & 25.8 & 336 & 23.8 & 328 & 23.2 & 333 & 23.8 & 334 & 23.8 & 334 \\
\hline Vinjeøra & & & 25.6 & 329 & 24.3 & 332 & 24.9 & 333 & 24.9 & 333 \\
\hline Andalsnes & 22.7 & 327 & 22.6 & 323 & 22.8 & 328 & 23.7 & 330 & 23.7 & 329 \\
\hline Stranda & 21.8 & 330 & 21.4 & 321 & 21.6 & 326 & 22.9 & 328 & 22.9 & 328 \\
\hline St15 & 24.5 & 326 & & & 22.8 & 337 & 19.0 & 346 & 23.2 & 338 \\
\hline St16 & 24.0 & 329 & & & 23.7 & 338 & 21.6 & 348 & 24.1 & 338 \\
\hline
\end{tabular}




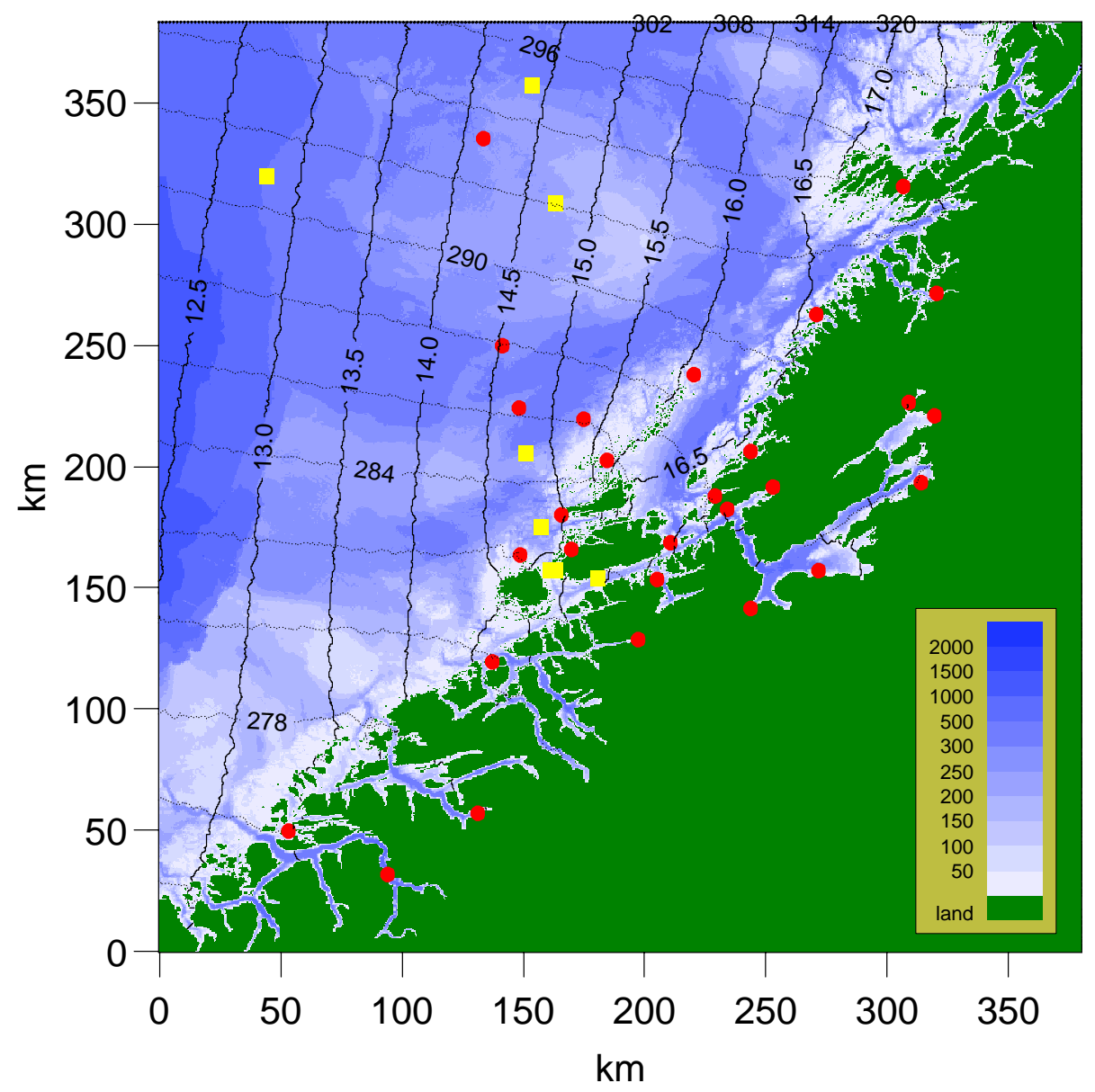

Figure 7: $N_{2}$ sea surface elevation. Isolines for amplitude (solid lines, 0.5-cm separation) and phase (broken lines, 2-degree separation). Shading shows depth with scale in legend (meter). Stations are marked as in figure 2.
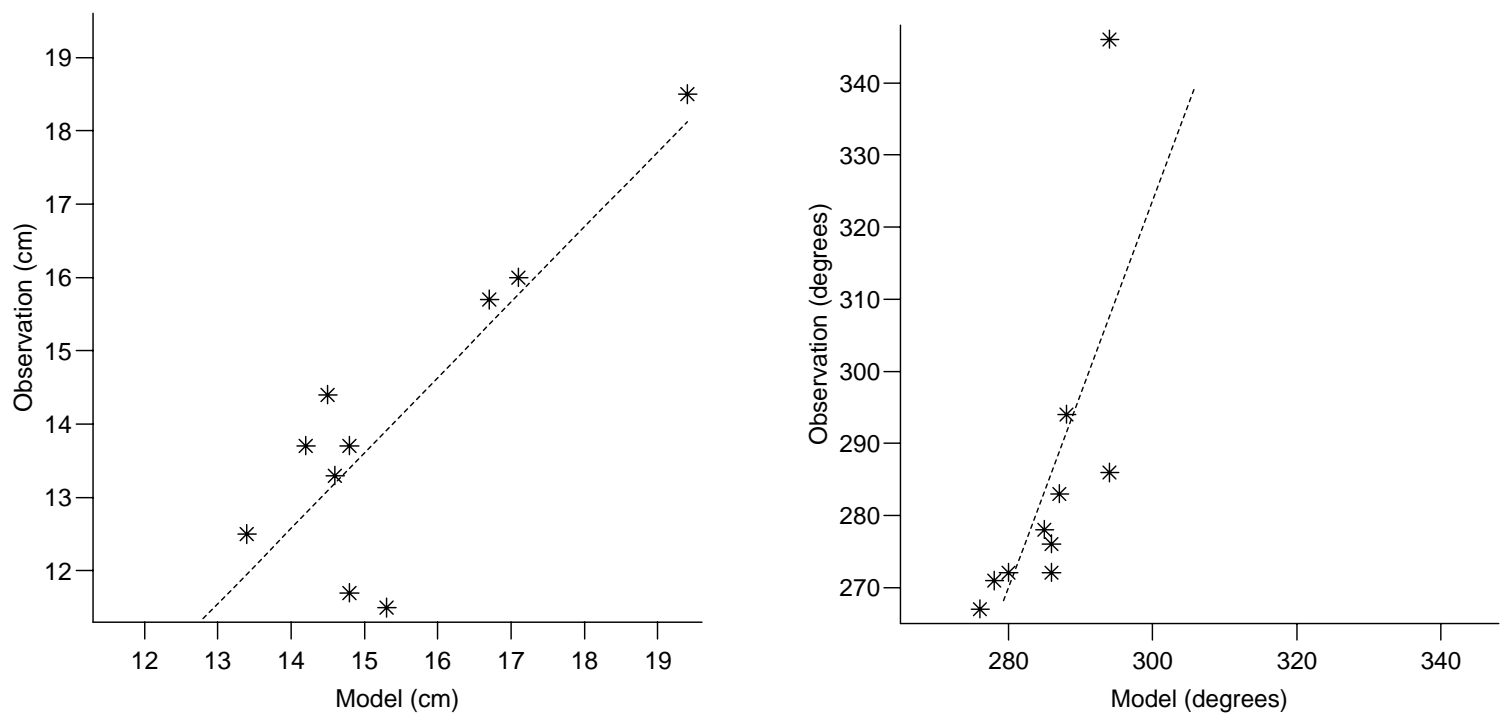

Figure 8: Scattering diagrams for $N_{2}$. Comparison between modelled and observed amplitude (left panel) and phase (right panel), for the elevation run. The least squares regression line (dashed). The standard deviation estimate between model and observation is $1.8 \mathrm{~cm}$ (amplitude) and 18.3 degrees (phase). 
Table 4: Harmonic constants for sea level $\left(N_{2}\right)$. Elevation $\left(h_{n}\right)$ is given in $\mathrm{cm}$, phase GMT $\left(g_{n}\right)$ in degrees. Measured and derived results in columns 2-5. Model results with just elevation, and both flux and elevation as exterior solution in columns 6-9. The latter also without bottom friction in columns 10-11.

\begin{tabular}{|c|c|c|c|c|c|c|c|c|c|c|}
\hline \multirow[t]{2}{*}{ Station } & \multicolumn{2}{|c|}{ Observed } & \multicolumn{2}{|c|}{ Derived } & \multicolumn{2}{|c|}{ Elevation } & \multicolumn{2}{|c|}{$\begin{array}{l}\text { Elevation } \\
\text { E Flux }\end{array}$} & \multicolumn{2}{|c|}{$\begin{array}{l}\text { Without } \\
\text { Friction }\end{array}$} \\
\hline & $h_{n}$ & $g_{n}$ & $\overline{h_{n}}$ & $g_{n}$ & $h_{n}$ & $g_{n}$ & $h_{n}$ & $g_{n}$ & $h_{n}$ & $g_{n}$ \\
\hline Rørvik & 16.0 & 286 & & & 17.1 & 294 & 17.3 & 295 & 17.3 & 295 \\
\hline Trondheim & 18.5 & 283 & & & 19.4 & 287 & 20.0 & 288 & 20.0 & 288 \\
\hline Heimsjøen & 15.7 & 278 & & & 16.7 & 285 & 17.1 & 286 & 17.1 & 286 \\
\hline Kristiansund & 13.7 & 272 & & & 14.8 & 280 & 15.2 & 281 & 15.2 & 281 \\
\hline Alesund & 12.5 & 267 & & & 13.4 & 276 & 14.2 & 277 & 14.2 & 277 \\
\hline Draugen & 13.3 & 294 & & & 14.6 & 288 & 14.9 & 289 & 14.9 & 289 \\
\hline Haltenbanken 1 & 13.7 & 346 & & & 14.2 & 294 & 14.3 & 294 & 14.3 & 294 \\
\hline Namsos & & & 15.7 & 280 & 17.1 & 292 & 17.4 & 293 & 17.4 & 293 \\
\hline Buholmråsa & & & 15.8 & 278 & 16.6 & 291 & 16.9 & 292 & 16.9 & 292 \\
\hline Halten Fyr & & & 15.4 & 283 & 16.1 & 289 & 16.4 & 290 & 16.4 & 290 \\
\hline Lysøysundet & & & 15.7 & 282 & 16.6 & 289 & 16.9 & 290 & 17.0 & 290 \\
\hline Steinkjer & & & 20.4 & 282 & 20.9 & 288 & 21.6 & 288 & 21.6 & 288 \\
\hline Malm & & & 21.1 & 282 & 21.0 & 288 & 21.7 & 288 & 21.7 & 288 \\
\hline Levanger & & & 19.8 & 288 & 20.3 & 287 & 20.8 & 288 & 20.8 & 288 \\
\hline Orkanger & & & 18.9 & 285 & 19.2 & 287 & 19.7 & 288 & 19.7 & 288 \\
\hline Ràkvàg & & & 17.4 & 274 & 18.3 & 288 & 18.8 & 288 & 18.8 & 288 \\
\hline Uthaug & & & 15.5 & 277 & 16.8 & 288 & 17.1 & 289 & 17.2 & 289 \\
\hline Brekstad & & & 17.5 & 283 & 18.2 & 288 & 18.5 & 288 & 18.5 & 288 \\
\hline Mausundvær & & & 14.9 & 272 & 15.9 & 286 & 16.2 & 286 & 16.2 & 286 \\
\hline Hestvika & & & 16.2 & 282 & 17.0 & 287 & 17.3 & 287 & 17.3 & 287 \\
\hline Titran & & & 13.8 & 270 & 15.0 & 284 & 15.3 & 284 & 15.3 & 284 \\
\hline Kvenvær & & & 13.8 & 273 & 15.2 & 283 & 15.4 & 284 & 15.4 & 284 \\
\hline Veidholm & & & 14.0 & 267 & 15.0 & 282 & 15.3 & 283 & 15.3 & 283 \\
\hline Vinjeøra & & & 15.0 & 268 & 15.6 & 281 & 15.9 & 282 & 15.9 & 282 \\
\hline Andalsnes & 14.4 & 271 & 13.3 & 263 & 14.5 & 278 & 15.1 & 279 & 15.1 & 279 \\
\hline Stranda & & & 12.6 & 261 & 13.8 & 276 & 14.4 & 277 & 14.4 & 277 \\
\hline St15 & 11.7 & 272 & & & 14.8 & 286 & 15.1 & 287 & 15.1 & 287 \\
\hline St16 & 11.5 & 276 & & & 15.3 & 286 & 15.6 & 287 & 15.6 & 287 \\
\hline
\end{tabular}




\subsubsection{The $K_{1}$ component}

The amplitude of sea surface displacement for the largest diurnal component, $K_{1}$, is small compared to $M_{2}$. The contour lines for amplitude and phase are shown in figure 9. We have plotted the ratio between $K_{1}$ and $M_{2}$ major axis and have found that in some areas, e.g. outer Sunnmøre and the Froan area (figure 13), the $K_{1}$ current dominates. More on this in the section on tidal currents, section 4.2.

The regression analysis between observed and model amplitude and phase shows a relatively large scatter particularly for phase (figure 10). Standard deviation is $2.0 \mathrm{~cm}$ for amplitude and 11.0 degrees for phase.

The modelled amplitudes are 20-30 percent higher than observed. To compensate for this we made a heuristic optimalization by reducing the amplitude of the exterior solution by 20 percent. This made amplitudes fit the observed much better (standard deviation is $0.7 \mathrm{~cm}$ ) and shows that we can gain much by systematically utilizing optimizing techniques and probably also by refining the exterior solutions, i.e. the input of the model.

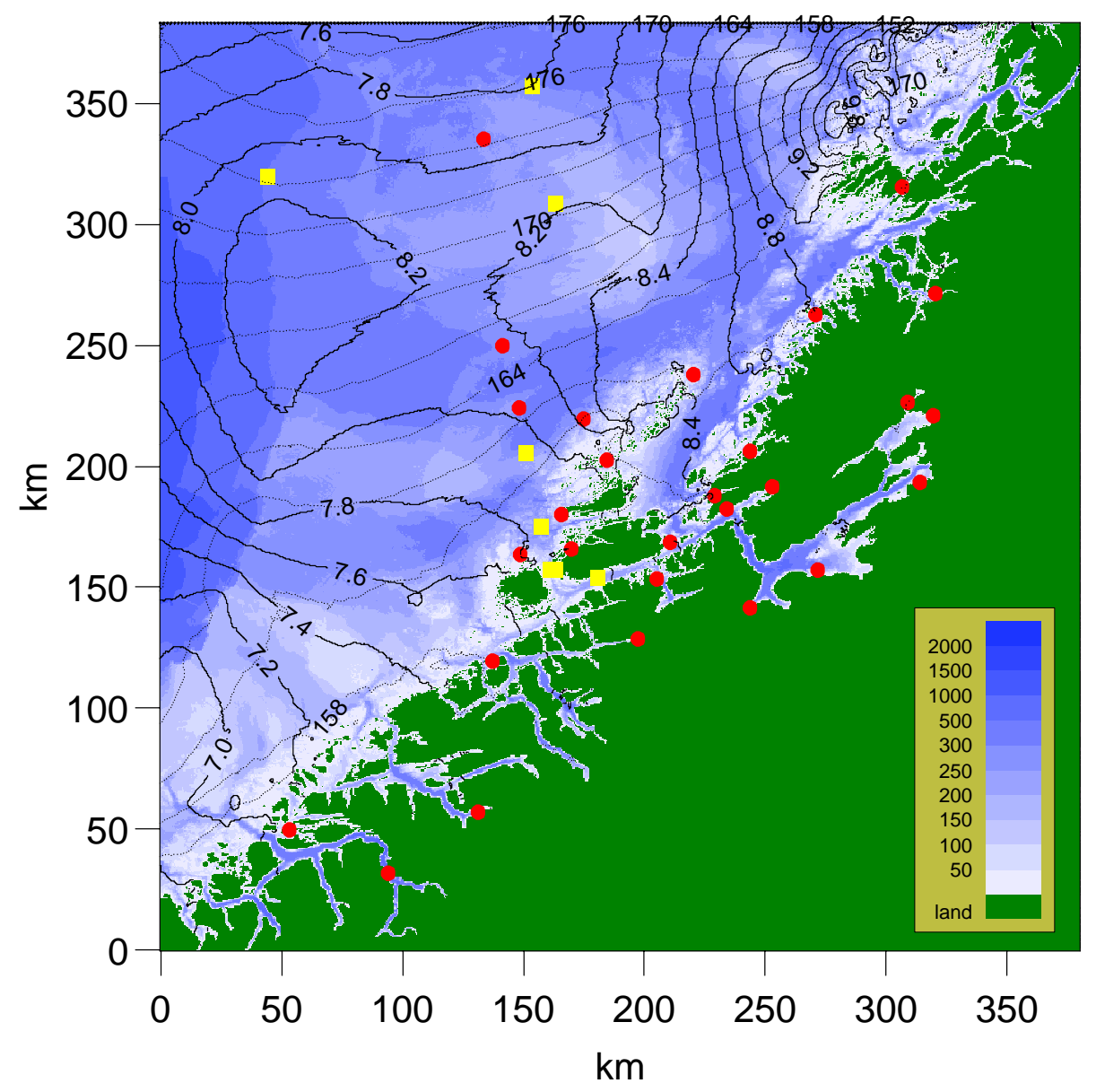

Figure 9: $K_{1}$ sea surface elevation. Isolines for amplitude (solid lines, 0.2-cm separation) and phase (broken lines, 2-degree separation). Shading shows depth with scale in legend (meter). Stations are marked as in figure 2. 
Table 5: Harmonic constants for sea level $\left(K_{1}\right)$. Elevation $\left(h_{n}\right)$ is given in $\mathrm{cm}$, phase GMT $\left(g_{n}\right)$ in degrees. Measured and derived results in columns 2-5. Model results with just elevation, and both flux and elevation as exterior solution in columns 6-9. The latter also without bottom friction in columns 10-11.

\begin{tabular}{|c|c|c|c|c|c|c|c|c|c|c|}
\hline \multirow[t]{2}{*}{ Station } & \multicolumn{2}{|c|}{ Observed } & \multicolumn{2}{|c|}{ Derived } & \multicolumn{2}{|c|}{ Elevation } & \multicolumn{2}{|c|}{$\begin{array}{l}\text { Elevation } \\
\text { \& Flux }\end{array}$} & \multicolumn{2}{|c|}{$\begin{array}{l}\text { Without } \\
\text { Friction }\end{array}$} \\
\hline & $h_{n}$ & $g_{n}$ & $h_{n}$ & $g_{n}$ & $h_{n}$ & $g_{n}$ & $h_{n}$ & $g_{n}$ & $h_{n}$ & $g_{n}$ \\
\hline Rørvik & 7.4 & 168 & & & 9.3 & 164 & 9.2 & 166 & 9.2 & 166 \\
\hline Trondheim & 6.7 & 166 & & & 8.7 & 159 & 9.0 & 162 & 9.0 & 162 \\
\hline Heimsjøen & 6.3 & 165 & & & 8.2 & 159 & 8.4 & 161 & 8.4 & 161 \\
\hline Kristiansund & 6.0 & 167 & & & 7.5 & 158 & 7.9 & 161 & 7.9 & 161 \\
\hline Alesund & 5.9 & 153 & & & 7.1 & 155 & 7.9 & 157 & 7.9 & 157 \\
\hline Draugen & 6.8 & 170 & & & 8.2 & 165 & 8.3 & 167 & 8.3 & 167 \\
\hline Haltenbanken 1 & 6.7 & 201 & & & 8.1 & 174 & 8.0 & 173 & 8.0 & 173 \\
\hline Namsos & 6.4 & 172 & 7.3 & 165 & 9.0 & 162 & 9.1 & 165 & 9.1 & 165 \\
\hline Buholmråsa & & & 7.3 & 164 & 8.9 & 162 & 9.0 & 164 & 9.0 & 164 \\
\hline Halten Fyr & 7.8 & 162 & 7.1 & 166 & 8.5 & 162 & 8.8 & 164 & 8.8 & 164 \\
\hline Lysøysundet & 5.8 & 163 & 7.3 & 166 & 8.5 & 160 & 8.8 & 163 & 8.8 & 163 \\
\hline Steinkjer & 7.1 & 175 & 7.4 & 165 & 8.8 & 159 & 9.2 & 162 & 9.2 & 162 \\
\hline Malm & 6.5 & 174 & 7.6 & 165 & 8.8 & 159 & 9.2 & 162 & 9.2 & 162 \\
\hline Levanger & 6.5 & 156 & 7.2 & 168 & 8.8 & 159 & 9.1 & 162 & 9.1 & 162 \\
\hline Orkanger & 4.8 & 182 & 6.8 & 167 & 8.7 & 159 & 9.0 & 162 & 9.0 & 162 \\
\hline Råkvåg & 6.5 & 158 & 6.3 & 161 & 8.6 & 160 & 8.9 & 162 & 8.9 & 162 \\
\hline Uthaug & 6.5 & 175 & 6.8 & 170 & 8.4 & 160 & 8.7 & 162 & 8.7 & 162 \\
\hline Brekstad & 7.8 & 156 & 7.7 & 173 & 8.6 & 160 & 8.9 & 162 & 8.9 & 162 \\
\hline Mausundvær & 6.3 & 164 & 6.5 & 167 & 8.2 & 160 & 8.4 & 162 & 8.4 & 162 \\
\hline Hestvika & 6.5 & 164 & 7.1 & 172 & 8.4 & 160 & 8.7 & 162 & 8.7 & 162 \\
\hline Titran & 5.9 & 152 & 6.1 & 166 & 7.9 & 159 & 8.2 & 161 & 8.2 & 161 \\
\hline Kvenvær & & & 6.1 & 168 & 7.9 & 159 & 8.2 & 161 & 8.2 & 161 \\
\hline Veidholm & 5.9 & 160 & 6.1 & 165 & 7.9 & 158 & 8.1 & 160 & 8.1 & 160 \\
\hline Vinjeøra & & & 6.6 & 165 & 7.8 & 158 & 8.1 & 161 & 8.1 & 161 \\
\hline Andalsnes & 7.9 & 178 & 5.8 & 162 & 7.5 & 158 & 8.0 & 161 & 8.0 & 161 \\
\hline Stranda & 5.8 & 149 & 5.5 & 161 & 7.2 & 155 & 7.9 & 157 & 7.9 & 157 \\
\hline St15 & 6.0 & 149 & & & 8.1 & 162 & 8.3 & 164 & 8.3 & 164 \\
\hline St16 & 6.7 & 157 & & & 8.3 & 160 & 8.6 & 162 & 8.6 & 162 \\
\hline
\end{tabular}
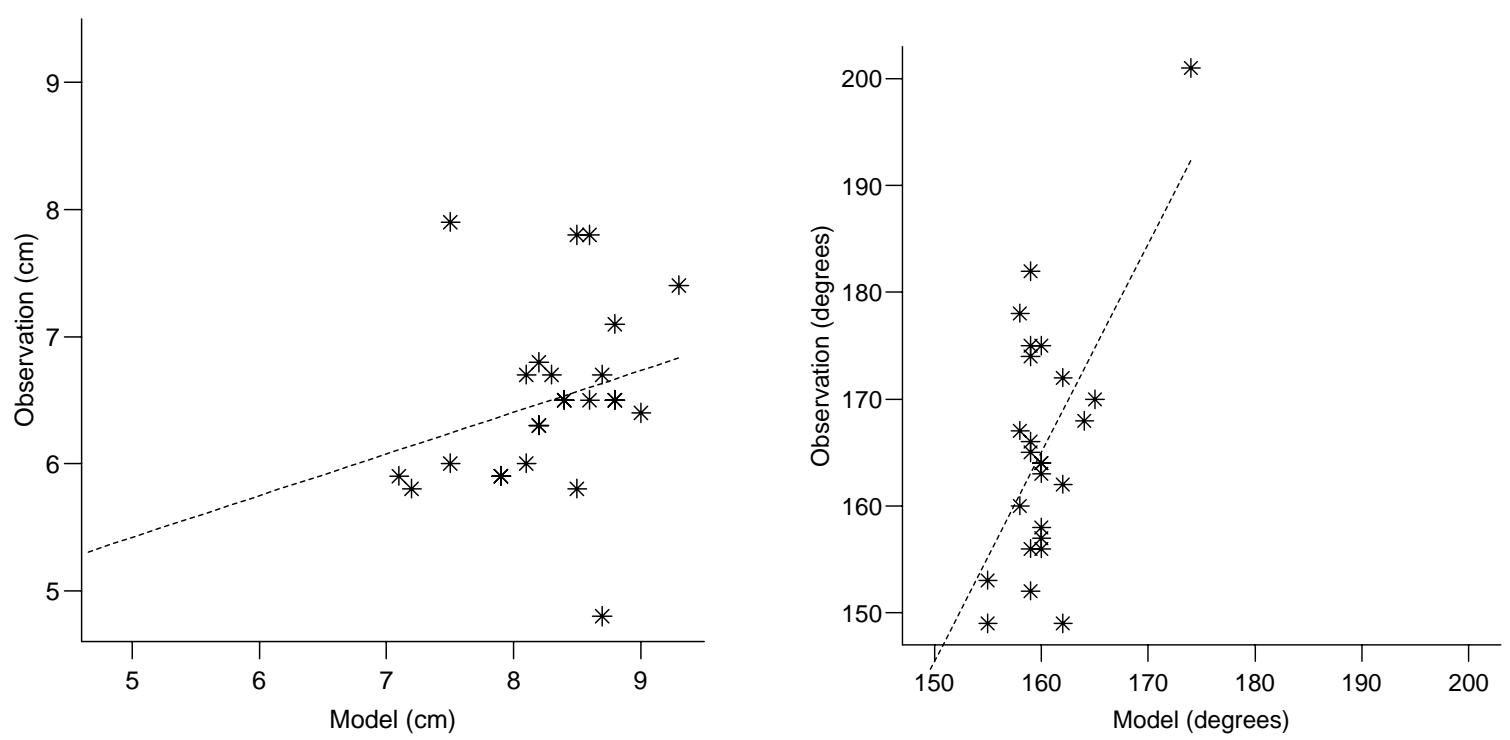

Figure 10: Scattering diagrams for $K_{1}$. Comparison between modelled and observed amplitude (left panel) and phase (right panel), for the elevation run. The least squares regression line (dashed). The standard deviation estimate between model and observation is $2.0 \mathrm{~cm}$ (amplitude) and 11.0 degrees (phase). 


\subsection{Tidal current}

Figures 11 and 12 show the $M_{2}$ and $K_{1}$ current ellipses and rotation directions for the simulation area. The model predicts relatively strong currents in the shallow areas along the coast for both components. For most parts the $M_{2}$ current is the larger, but as shown in figure 13 the $K_{1}$ dominates for some small areas. In the area north of Rørvik there are large currents for both $M_{2}$ and $K_{1}$. Being so close to the model boundary there may be artifacts.

We have limited our discussion of tidal currents to three areas: the Ramsøyfjord with the pipeline to Tjeldbergodden, Trondheimsleia the most trafficked sailing route, and the outer Sunnmøre area which show occurences of $K_{1}$ current dominance.

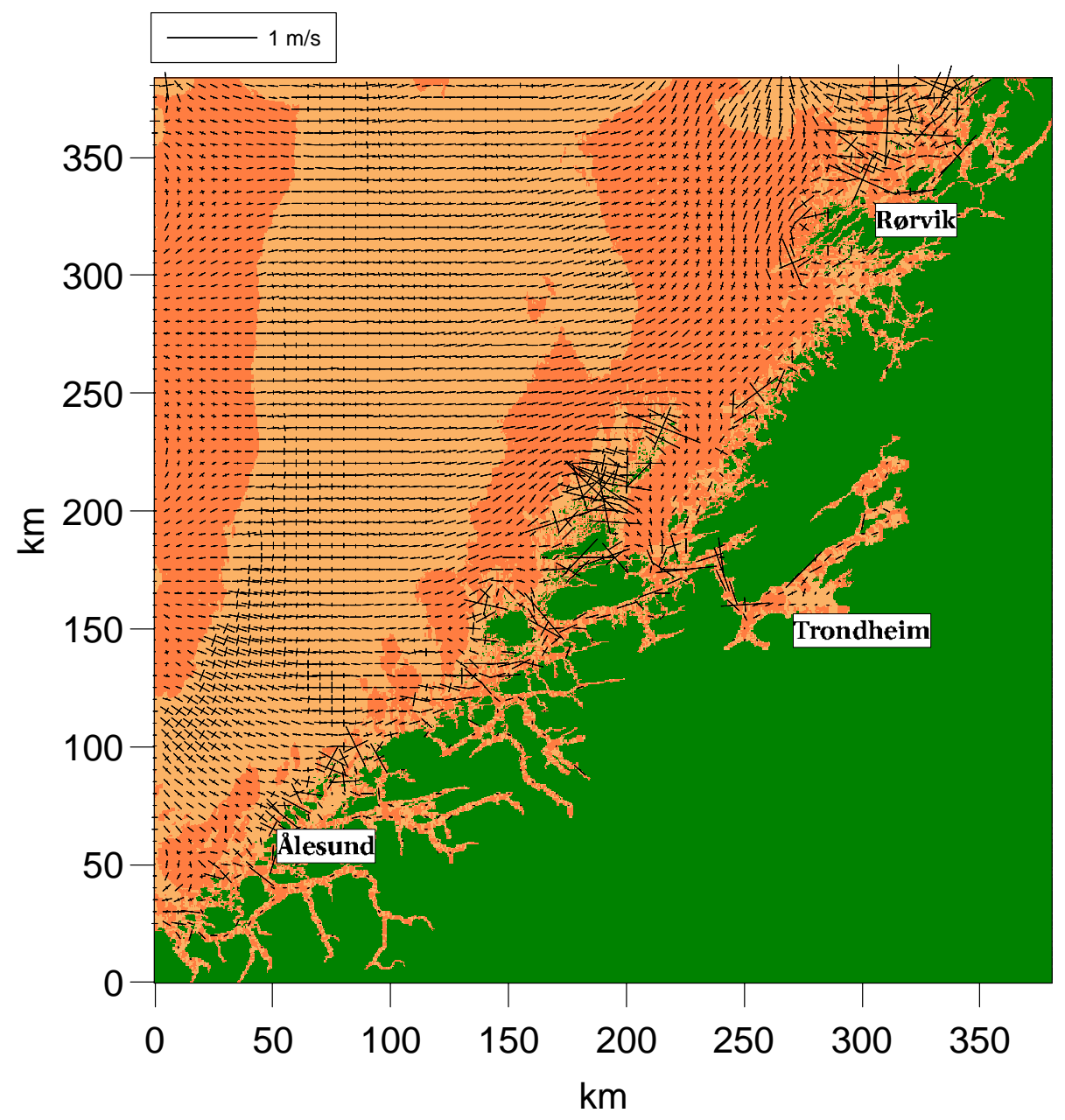

Figure 11: Tidal ellipse and rotation of the $M_{2}$ current vector. Bright shadowing clockwise rotation, darker shadowing counterclockwise. The crosses show the major and minor axes.

\subsubsection{Ramsøyfjorden}

For Ramsøyfjorden and out towards the Haltenbanken area there are current observations available from several stations which can be used for model validation. The results are presented in four tables, one for each tidal component, comparing the observed current values with the modelled values from the elevation driven simulations 


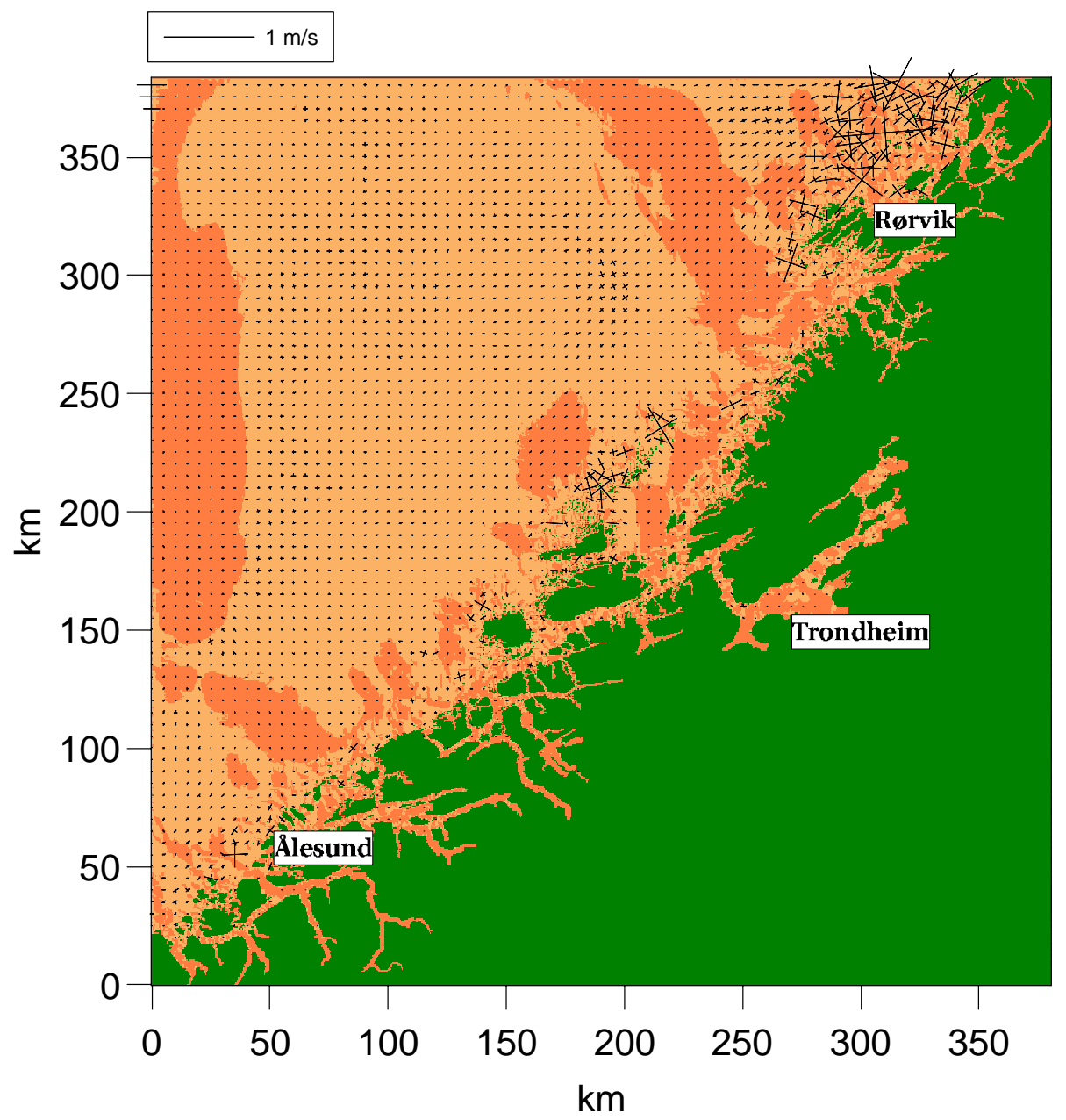

Figure 12: Tidal ellipse and rotation of the $K_{1}$ current vector. Bright shadowing clockwise rotation, darker shadowing counterclockwise. The crosses show the major and minor axes. 

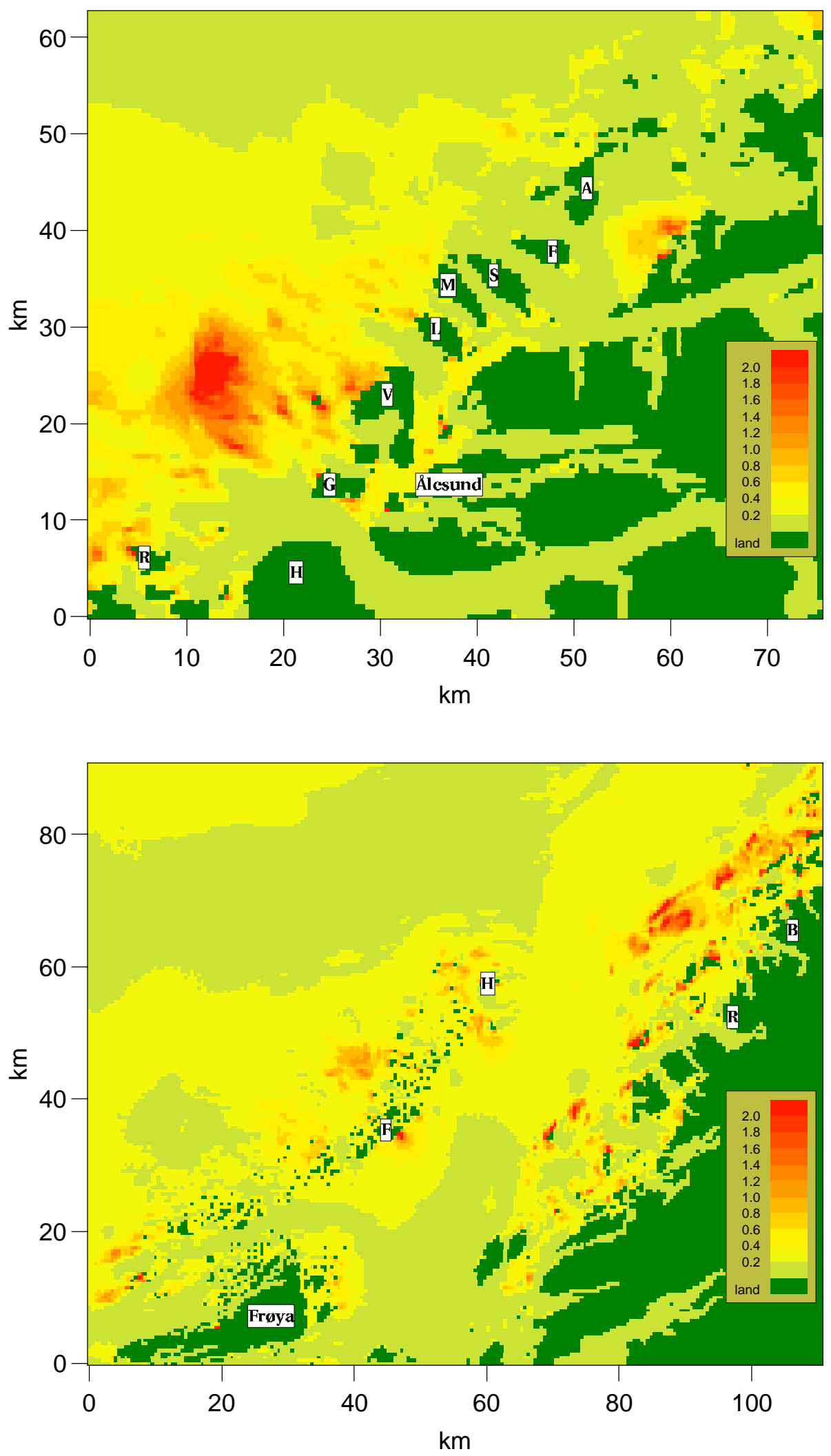

Figure 13: The ratio between the major axis of the current ellipses for the $K_{1}$ and $M_{2}$ components for the outer Sunnmøre area (Upper panel) and the Froan area (Lower Panel). Color scale in legend. Map codes, upper panel: H: Hareidlandet, R: Runde, G: Godøya, V: Vigra, L: Løvsøya, M: Haramsøya, S: Skuløya, F: Fjørtoft and A: Harøya. Map codes, lower panel: F: Froan, H: Halten Fyr, R: Roan and B: Bessaker. 
(tables 6-9). For most of the stations along the Tjeldbergodden pipeline (St04 - St16, table 1) current measurements were made by sensors 3-5 meters above the sea bed. When only near bottom measurements are available we have estimated a depth mean current by assuming a boundary layer profile, Schlichting (1979), which is used for comparison with model data. The mean current is taken to be $\bar{v} \sim v_{i}\left(\frac{h}{\Delta h}\right)^{\frac{1}{10}}$, here $\bar{v}$ is the mean current, $v_{i}$ the measured current, $h$ the total depth and $\Delta h$ the height of the current meter above the sea bed. Here $\Delta h$ is 3 meters for all stations. For station St07 measurements are available for three depths through the water column. We used the data from 51 meters above the sea bed which seemed to be a representative mean value. For the semi-diurnal components the modelled peak currents, represented with the major half axes, are in good agreement with observations for most of the stations. For the the other ellipse parameters, minor half axis, orientation and rotation the agreement is not so good. The boundary layer approximation we made could have contributed to these discrepancies so could also stratification effects. The diurnal, $K_{1}$, peak current is small for most stations; the model seems to underestimate the diurnal current.

In figure 14 we show the $M_{2}$ current fields at the times of peak incoming and outgoing tidal currents. The tidal ellipse and rotation for the current vector and the maximum current (major half axis) for $M_{2}$ and $K_{1}$ are shown in figures 15 and 16 respectively.

Table 6: Parameters for the $M_{2}$ current ellipse. A $(\mathrm{cm} / \mathrm{s})$, major half axis; B $(\mathrm{cm} / \mathrm{s})$, minor half axis; $\theta$, orientation of major axis in degrees true; Rot., Rotation direction for the current vector ( + , clockwise; -, counterclockwise). Total depths are included for some of the stations.

\begin{tabular}{|l|r|r|r|r|r|r|r|c|}
\hline \multirow{2}{*}{$\begin{array}{l}\text { Station } \\
\text { (map code) }\end{array}$} & \multicolumn{4}{|c|}{ Observed } & \multicolumn{5}{|c|}{ Model } \\
\cline { 2 - 9 } & A & B & $\theta$ & Rot. & A & B & $\theta$ & Rot. \\
\hline St04 $(230 \mathrm{~m})$ & 9.1 & 1.1 & 33 & - & 8.8 & 0.1 & 25 & + \\
\hline St07 $(151 \mathrm{~m})$ & 15.7 & 0.1 & 99 & + & 12.7 & 1.5 & 101 & + \\
\hline St09 $(75 \mathrm{~m})$ & 3.5 & 2.0 & 44 & - & 9.6 & 0.1 & 139 & - \\
\hline St11 $(300 \mathrm{~m})$ & 2.8 & 1.8 & 111 & - & 3.2 & 0.8 & 166 & - \\
\hline St13(275m) & 4.3 & 2.7 & 33 & - & 5.4 & 0.5 & 39 & - \\
\hline St15(257m) & 8.1 & 0.2 & 4 & - & 6.4 & 0.1 & 14 & + \\
\hline St16(219m) & 5.2 & 0.2 & 17 & - & 5.8 & 2.2 & 14 & - \\
\hline Draugen & 8.5 & 3.7 & 359 & + & 6.7 & 0.7 & 6 & + \\
\hline Haltenbanken 1 & 5.6 & 0.7 & 354 & + & 6.8 & 1.3 & 4 & + \\
\hline Haltenbanken 2 & 10.0 & 1.7 & 112 & - & 6.2 & 0.4 & 11 & + \\
\hline Haltenbanken 3 & 5.3 & 1.2 & 185 & - & 6.5 & 1.0 & 6 & + \\
\hline Helland Hansen & 4.8 & 0.9 & 27 & + & 4.4 & 0.3 & 13 & - \\
\hline
\end{tabular}


Table 7: Parameters for the $K_{1}$ Current Ellipse. A $(\mathrm{cm} / \mathrm{s})$, major half axis; B $(\mathrm{cm} / \mathrm{s})$, minor half axis; $\theta$, orientation of major axis in degrees true; Rot., Rotation direction for the current vector ( + , clockwise; -, counterclockwise). Total depths are included for some of the stations.

\begin{tabular}{|l|r|r|r|r|r|r|r|c|}
\hline \multirow{2}{*}{$\begin{array}{l}\text { Station } \\
\text { (map code) }\end{array}$} & \multicolumn{4}{|c|}{ Observed } & \multicolumn{4}{|c|}{ Model } \\
\cline { 2 - 10 } & A & B & $\theta$ & Rot. & A & B & $\theta$ & Rot. \\
\hline St04 $(230 \mathrm{~m})$ & 0.4 & 0.1 & 61 & - & 0.9 & 0.0 & 25 & + \\
\hline St07 $(151 \mathrm{~m})$ & 1.3 & 0.1 & 92 & + & 0.7 & 0.1 & 110 & + \\
\hline St09 $(75 \mathrm{~m})$ & 2.0 & 0.1 & 0 & + & 0.5 & 0.0 & 138 & - \\
\hline St11 $(300 \mathrm{~m})$ & 1.2 & 0.2 & 105 & + & 0.3 & 0.0 & 21 & - \\
\hline St13(275m) & 1.4 & 0.2 & 42 & + & 1.2 & 0.3 & 46 & + \\
\hline St15(257m) & 1.8 & 1.0 & 44 & + & 1.3 & 0.3 & 31 & + \\
\hline St16(219m) & 3.0 & 1.9 & 43 & + & 1.1 & 0.8 & 30 & - \\
\hline Draugen & 1.4 & 0.8 & 350 & + & 1.3 & 0.4 & 21 & + \\
\hline Helland Hansen & 3.2 & 1.2 & 179 & + & 1.3 & 0.4 & 178 & + \\
\hline
\end{tabular}

Table 8: Parameters for the $S_{2}$ Current Ellipse. A $(\mathrm{cm} / \mathrm{s})$, major half axis; B $(\mathrm{cm} / \mathrm{s})$, minor half axis; $\theta$, orientation of major axis in degrees true; Rot., Rotation direction for the current vector ( + , clockwise; -, counterclockwise). Total depths are included for some of the stations.

\begin{tabular}{|l|r|r|r|r|r|r|r|c|}
\hline \multirow{2}{*}{$\begin{array}{l}\text { Station } \\
\text { (map code) }\end{array}$} & \multicolumn{4}{|c|}{ Observed } & \multicolumn{4}{|c|}{ Model } \\
\cline { 2 - 10 } & A & B & $\theta$ & Rot. & A & B & $\theta$ & Rot. \\
\hline St04 $(230 \mathrm{~m})$ & 4.9 & 1.1 & 33 & - & 3.0 & 0.0 & 25 & + \\
\hline St07 $(151 \mathrm{~m})$ & 5.7 & 0.2 & 99 & + & 4.4 & 0.4 & 100 & + \\
\hline St09 $(75 \mathrm{~m})$ & 2.5 & 1.1 & 176 & - & 3.2 & 0.1 & 139 & - \\
\hline St11 $(300 \mathrm{~m})$ & 1.4 & 0.9 & 100 & - & 1.1 & 0.3 & 167 & - \\
\hline St13(275m) & 1.3 & 0.9 & 15 & - & 1.8 & 0.2 & 40 & - \\
\hline St15(257m) & 2.8 & 0.2 & 20 & - & 2.1 & 0.0 & 15 & - \\
\hline St16(219m) & 2.4 & 0.0 & 24 & - & 1.9 & 0.7 & 14 & - \\
\hline Draugen & 3.3 & 0.5 & 1 & + & 2.2 & 0.1 & 7 & + \\
\hline Helland Hansen & 2.2 & 0.5 & 86 & + & 1.8 & 0.1 & 24 & + \\
\hline
\end{tabular}

Table 9: Parameters for the $N_{2}$ Current Ellipse. A $(\mathrm{cm} / \mathrm{s})$, major half axis; B $(\mathrm{cm} / \mathrm{s})$, minor half axis; $\theta$, orientation of major axis in degrees true; Rot., Rotation direction for the current vector ( + , clockwise; -, counterclockwise). Total depths are included for some of the stations.

\begin{tabular}{|l|r|r|r|r|r|r|r|c|}
\hline \multirow{2}{*}{$\begin{array}{l}\text { Station } \\
\text { (map code) }\end{array}$} & \multicolumn{4}{|c|}{ Observed } & \multicolumn{5}{|c|}{ Model } \\
\cline { 2 - 10 } & A & B & $\theta$ & Rot. & A & B & $\theta$ & Rot. \\
\hline St04 $(230 \mathrm{~m})$ & 1.8 & 0.4 & 27 & - & 1.8 & 0.0 & 25 & + \\
\hline St07 $(151 \mathrm{~m})$ & 2.9 & 0.2 & 91 & + & 2.6 & 0.2 & 100 & + \\
\hline St09 $(75 \mathrm{~m})$ & 1.2 & 0.2 & 7 & + & 1.8 & 0.0 & 139 & - \\
\hline St11 $(300 \mathrm{~m})$ & 1.0 & 0.2 & 90 & + & 0.6 & 0.2 & 171 & - \\
\hline St $13(275 \mathrm{~m})$ & 1.2 & 0.4 & 54 & - & 1.2 & 0.1 & 41 & - \\
\hline St15(257m) & 1.6 & 0.1 & 157 & + & 1.3 & 0.0 & 16 & + \\
\hline St $16(219 \mathrm{~m})$ & 1.3 & 0.5 & 54 & + & 1.2 & 0.4 & 13 & - \\
\hline Helland Hansen & 1.3 & 0.3 & 84 & + & 1.1 & 0.1 & 37 & + \\
\hline
\end{tabular}



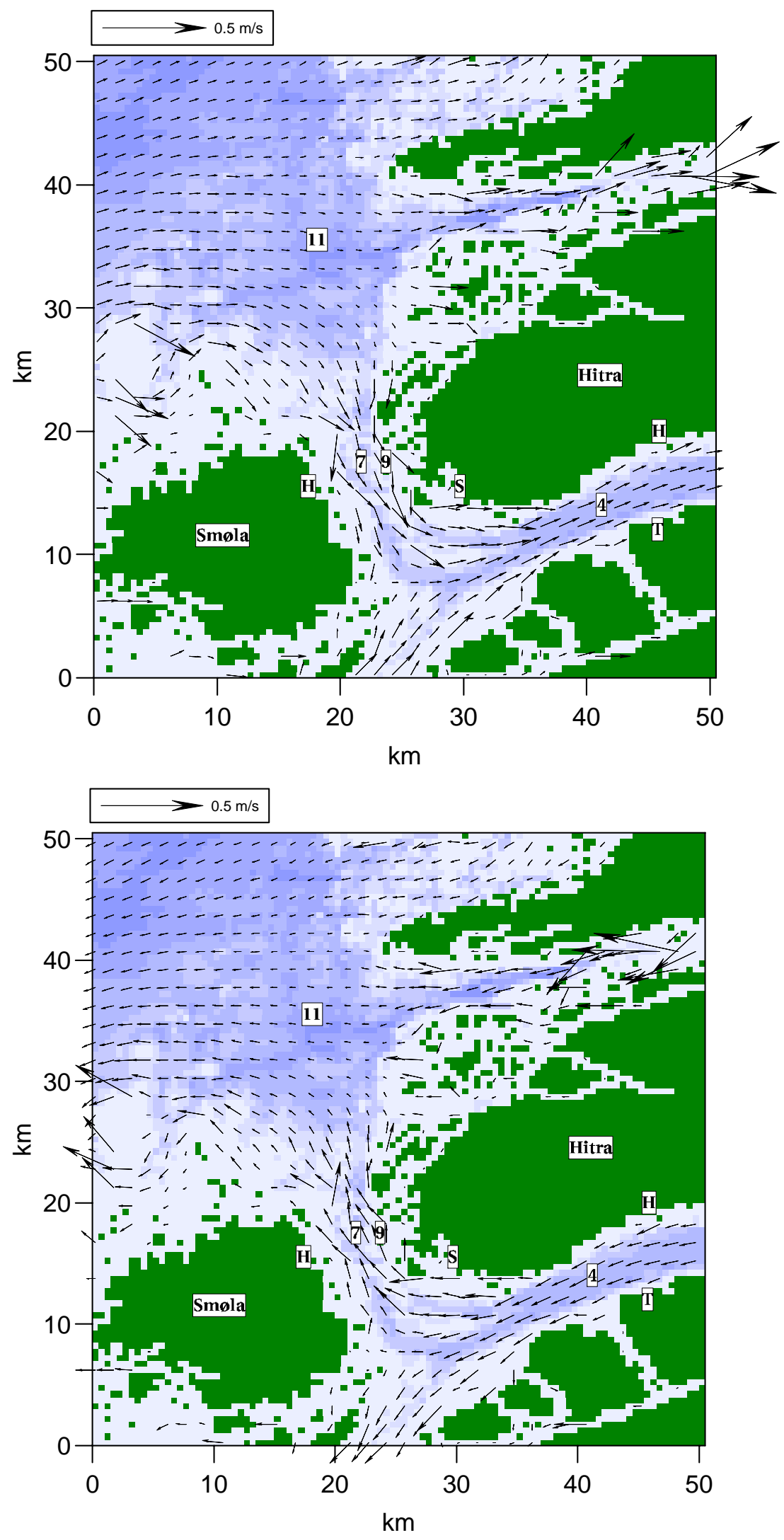

Figure 14: Upper panel: $M_{2}$ current field at the time of peak incoming current of the Ramsøyfjorden area. Lower panel: $M_{2}$ current field at the time of peak outgoing current. Map codes: 4 corresponds to St04, 7 to St07, 9 to St09 and 11 to St11. We have also indicated two cross-sections: H-S: Ramsøyfjorden, T-H: Tjeldbergodden. 

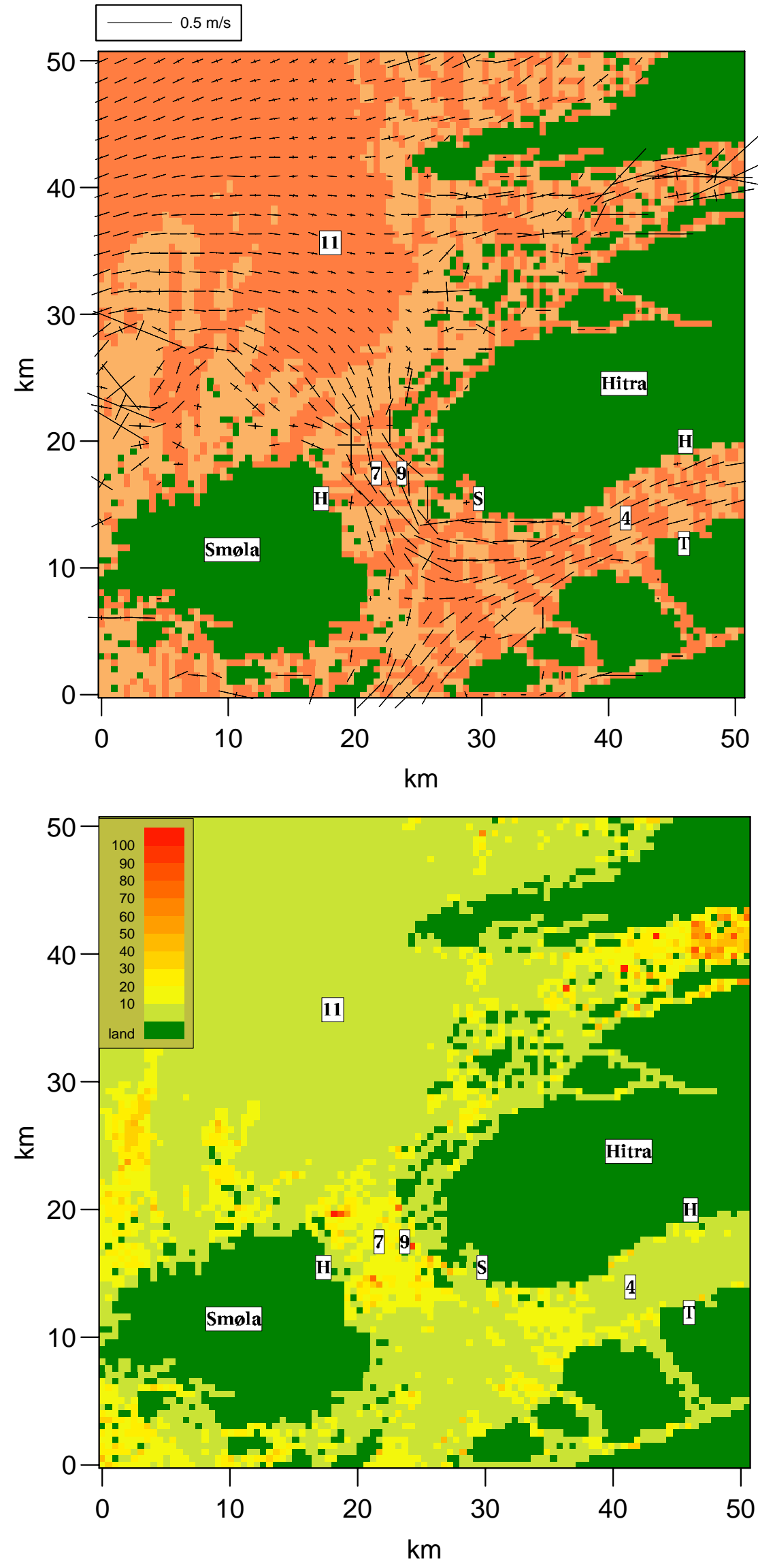

Figure 15: Upper panel: Tidal ellipse and rotation of the $M_{2}$ current vector. Bright shadowing clockwise rotation, darker shadowing counterclockwise at the Ramsøyfjorden area. The crosses show the major and minor axis. Color scale in $\mathrm{cm} / \mathrm{s}$, legend. Lower panel: Maximum $M_{2}$ current (major half axis). Map codes as in figure 14 . 

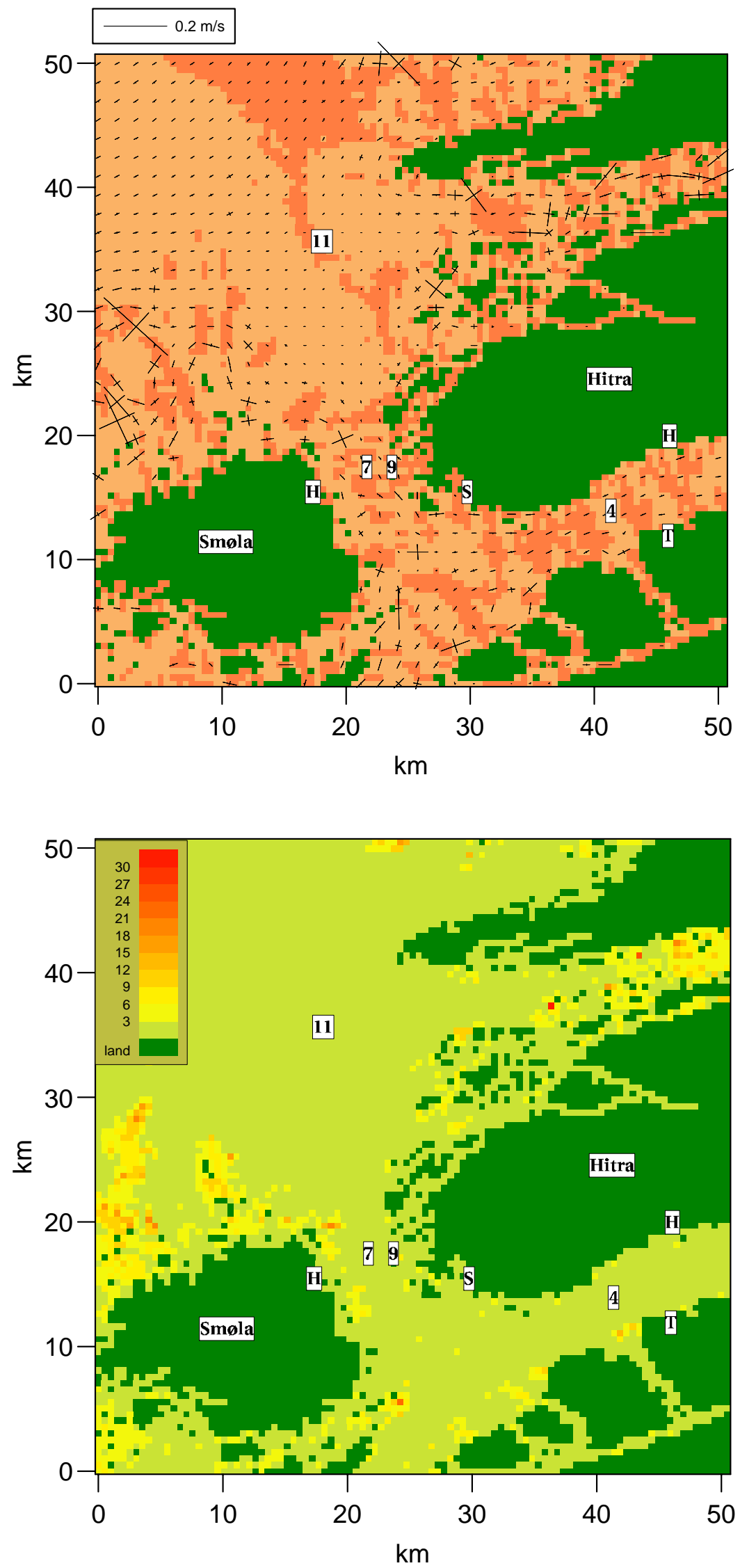

Figure 16: Upper panel: Tidal ellipse and rotation of the $K_{1}$ current vector. Bright shadowing clockwise rotation, darker shadowing counterclockwise at the Ramsøyfjorden area. The crosses show the major and minor axis. Color scale in $\mathrm{cm} / \mathrm{s}$, legend. Lower panel: Maximum $K_{1}$ current (major half axis). Map codes as in figure 14 . 


\subsubsection{Trondheimsleia}

The channel between the island Hitra and the mainland is called Trondheimsleia (the lead to Trondheim). The long Trondheimsfjord with total length of $120 \mathrm{~km}$ stretches from Agdenes at the mouth towards Trondheim and further inwards to Steinkjer (map code 12, figure 2). This fjord system is important for ship traffic along the coast. The large surface area of Trondheimsfjorden and the influx from several large rivers imply a large water exchange through the relatively narrow mouth at Agdenes. In figure 17 the $M_{2}$ current fields at the times of peak incoming and outgoing tidal currents are shown for this area. The figure shows strong currents in the shallower parts of the fjord, and also substantial currents for deeper parts of Trondheimsleia and Trondheimsfjorden. Figures 18 and 19 show the tidal ellipse and rotation for the current vector and the maximum current (major half axis) for $M_{2}$ and $K_{1}$ respectively. The $M_{2}$ current dominates the $K_{1}$ current in Trondheimsfjorden.

\subsubsection{Volume fluxes through key cross-sections}

For some main channels between the larger islands near the entrance to Trondheimsfjorden we have calculated the peak $M_{2}$ volume flux $(Q)$ through cross-sections of the channels (table 10, figures 14 and 17). A mean peak current speed for the cross-sections is calculated and may serve as a more robust measure of the current speed than values from single grid points. The time delay $(\Delta T)$ from local high water to peak volume flux is also calculated and the results are displayed in table 10.

Table 10: Peak $M_{2}$ volume flux. Area of cross-section $S\left(\mathrm{~m}^{2}\right)$; Volume flux $Q\left(\mathrm{~m}^{3} / \mathrm{s}\right)$; Mean peak speed $U_{s}=Q / S(\mathrm{~cm} / \mathrm{s})$; Time delay $\Delta T$ (hours).

\begin{tabular}{|c|c|c|c|c|}
\hline Cross-section & $S$ & $Q$ & $U_{s}$ & $\Delta T$ \\
\hline Ramsøyfjorden (H-S) & $6.3 \cdot 10^{5}$ & $6.1 \cdot 10^{4}$ & 9.6 & 3.5 \\
\hline Tjeldbergodden (T-H) & $9.9 \cdot 10^{5}$ & $7.3 \cdot 10^{4}$ & 7.4 & 4.0 \\
\hline Agdenes (A-R) & $1.5 \cdot 10^{6}$ & $1.8 \cdot 10^{5}$ & 12.5 & 3.1 \\
\hline Frøyfjorden (D-F) & $4.1 \cdot 10^{4}$ & $1.0 \cdot 10^{5}$ & 39.8 & 3.9 \\
\hline
\end{tabular}

The mean peak current speed in the cross-section in Ramsøyfjorden (H-S in figure 14) fits well between the measured values of stations St07 and St09 located near the cross-sections. The time delay between modelled local high water and peak volume flux in this cross-section is about 3.5 hours indicating a standing wave oscillation in this area. Mean peak current speed in cross-section near Tjeldbergodden ( $\mathrm{T}-\mathrm{H}$ in figure 14) is in good agreement with the measurement from station St04. In crosssection D-F (figure 17), Frøyfjorden, current measurements are available from position $63.40 N, 8.48 E$, Mathisen et al. (1997). The mean major axis was measured to 49.8 $\mathrm{cm} / \mathrm{s}$ in good agreement the mean speed in table 10 . No current measurements in the deep channel near Agdenes, cross-section A-R (figure 17), are available to us to compare with the modelled current. 

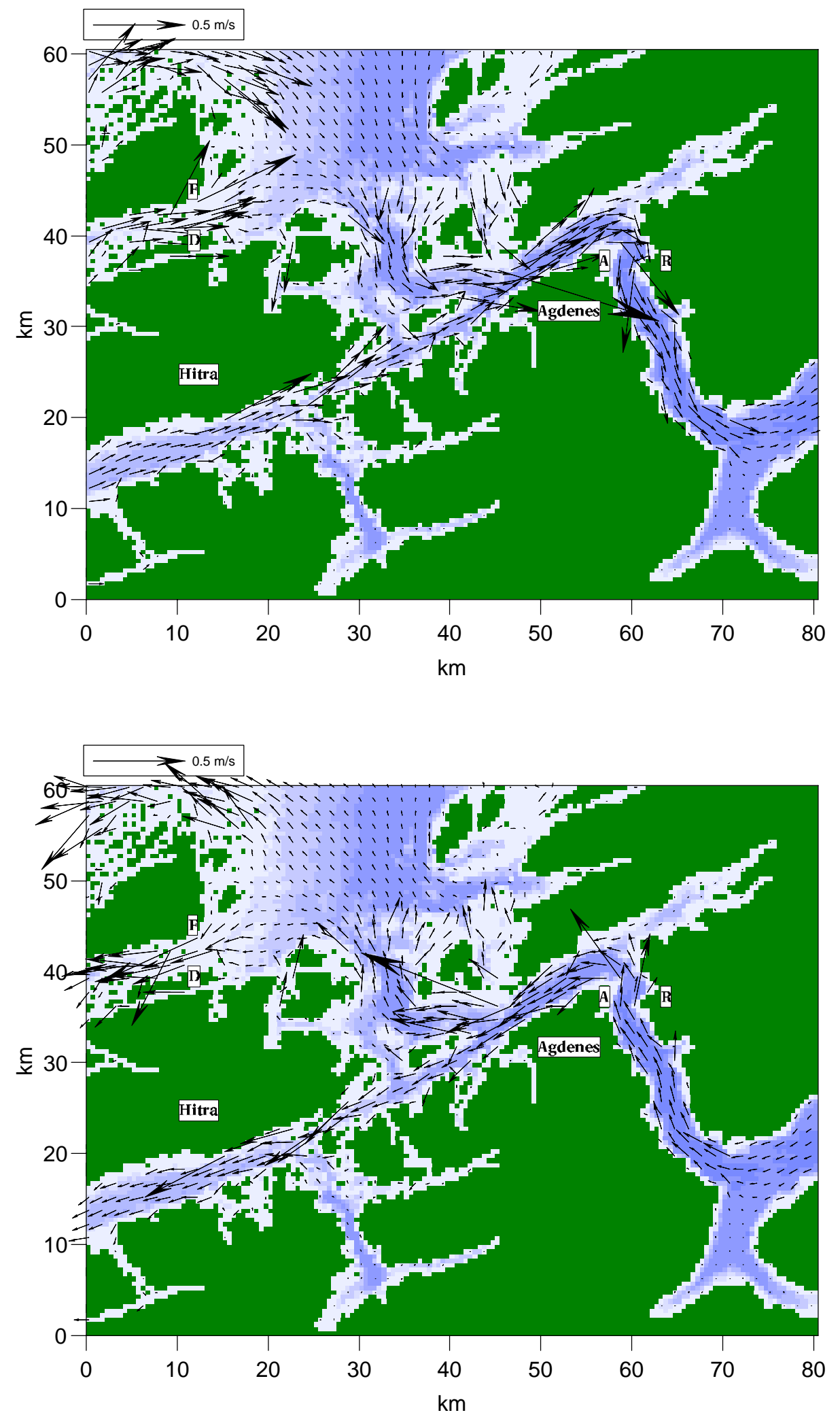

Figure 17: Upper panel: $M_{2}$ current field at the time of peak incoming current at the Trondheimsleia area. Lower panel: $M_{2}$ current field at the time of peak outgoing current. Two cross-sections: A-R: Agdenes and D-F: Frøyfjorden, are marked. 

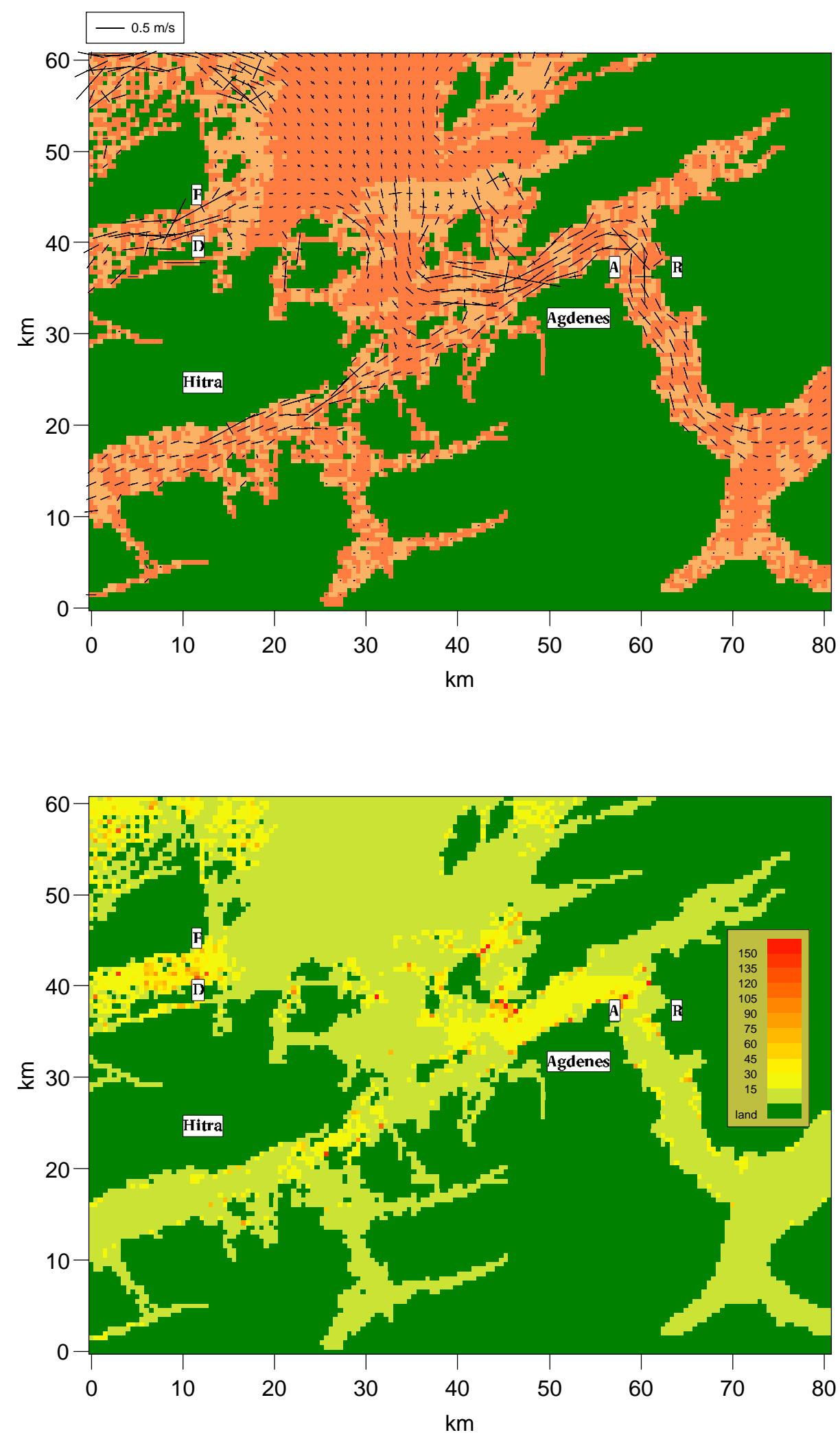

Figure 18: Upper panel: Tidal ellipse and rotation of the $M_{2}$ current vector. Bright shadowing clockwise rotation, darker shadowing counterclockwise at the Trondheimsleia area. The crosses show the major and minor axis. Color scale in $\mathrm{cm} / \mathrm{s}$, legend. Lower panel: Maximum $M_{2}$ current (major half axis). Map codes as in figure 17. 

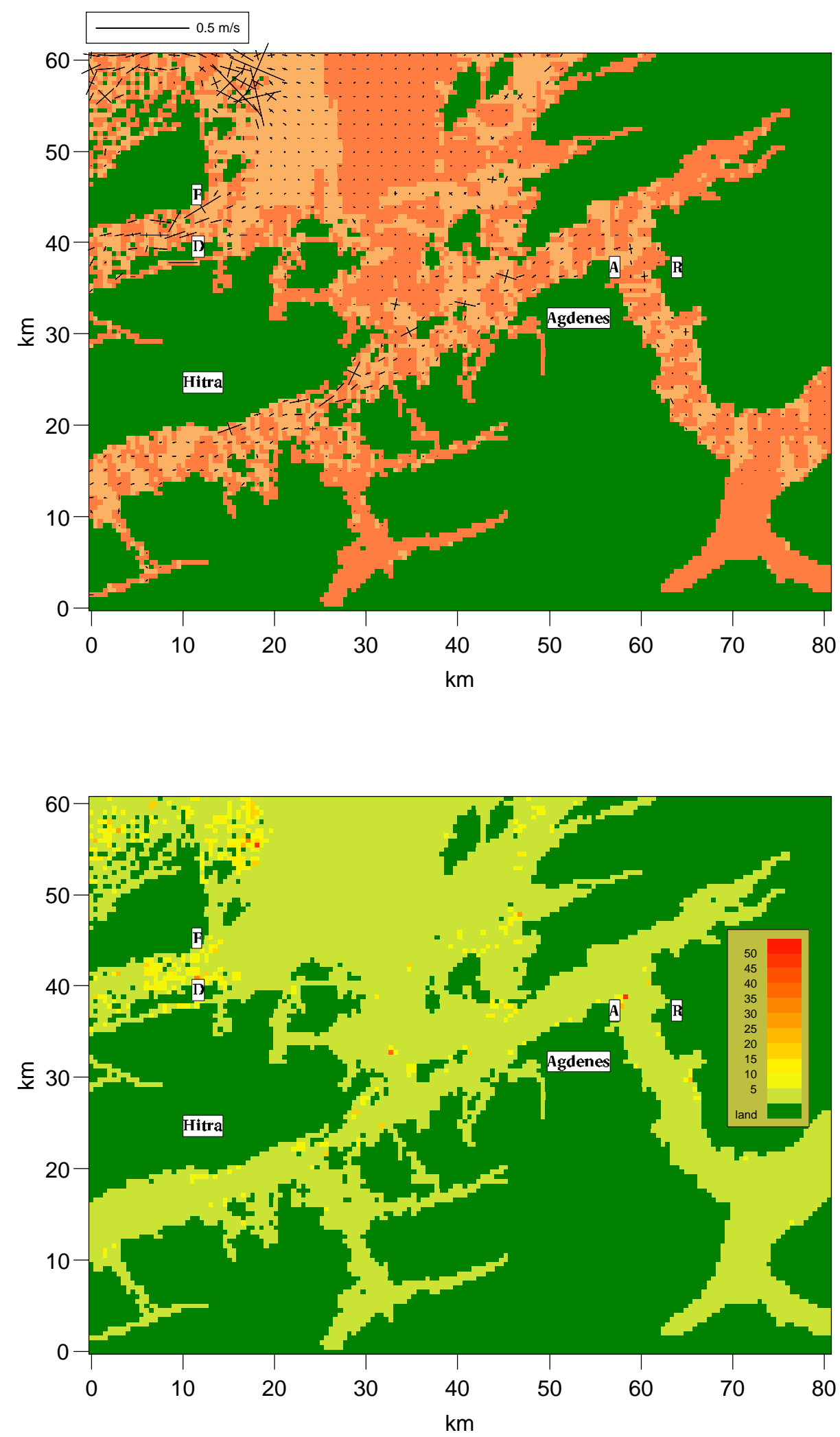

Figure 19: Upper panel: Tidal ellipse and rotation of the $K_{1}$ current vector. Bright shadowing clockwise rotation, darker shadowing counterclockwise at the Trondheimsleia area. The crosses show the major and minor axis. Color scale in $\mathrm{cm} / \mathrm{s}$, legend. Lower panel: Maximum $K_{1}$ current (major half axis). Map codes as in figure 17. 


\subsubsection{Outer Sunnmøre}

The outer Sunnmøre area with the region center located in the Jugend town Alesund, one of Norway's largest fishery harbors, is an important economic region. An interesting pattern is seen in the current field at Nordøyane, the chain of islands north of Alesund (labels A-G, figures 20 and 22). The figures show the current fields at the times of peak incoming and outgoing tidal currents for $M_{2}$ and $K_{1}$ respectively. The tidal ellipse and rotation for the current vector and the maximum current (major half axis) for $M_{2}$ and $K_{1}$ are depicted in figures 21 and 23 respectively.

As revealed by figure 13 and by visual inspection from the current plots (figures 20 and 22) the $K_{1}$ current is bigger than $M_{2}$ in the southern part of Nordøyane. We can clearly see a vortex in the $K_{1}$ current west of the islands Godøya and Vigra and some vortical structures further north. One should note the special topographic feature with the fjord ending between Hareidlandet and Godøya continuing as a trench far into the shelf south of the vortex. A branch of the trench goes northward to the west of the vortex. Between the island Vigra and the northern branch of the trench the depth is very shallow. Obviously the formation of the vortex structure is linked to bottom topography in the area.

In the northern part of Nordøyane there is a strong $M_{2}$ current running in the channels between the islands in interaction with the flow in and out of the wide fjords of Romsdal. In this part there is a clear $M_{2}$ dominance.

In order to understand the vortex in the $K_{1}$ current we have investigated the possibility for shelf waves with 24 hours period for depth profiles as outside the island Vigra. We find that such a wave is possible for a profile starting starting right off the west coast of Vigra going west to the end of the plotting area. In figure 24 the bottom topography is made uniform in the north-south direction and the current field for the corresponding 24 hours period shelf wave is superimposed. Although this is a simple model it captures some of the features in figure 22 indicating that the strong $K_{1}$ is due to the shelf topography. 

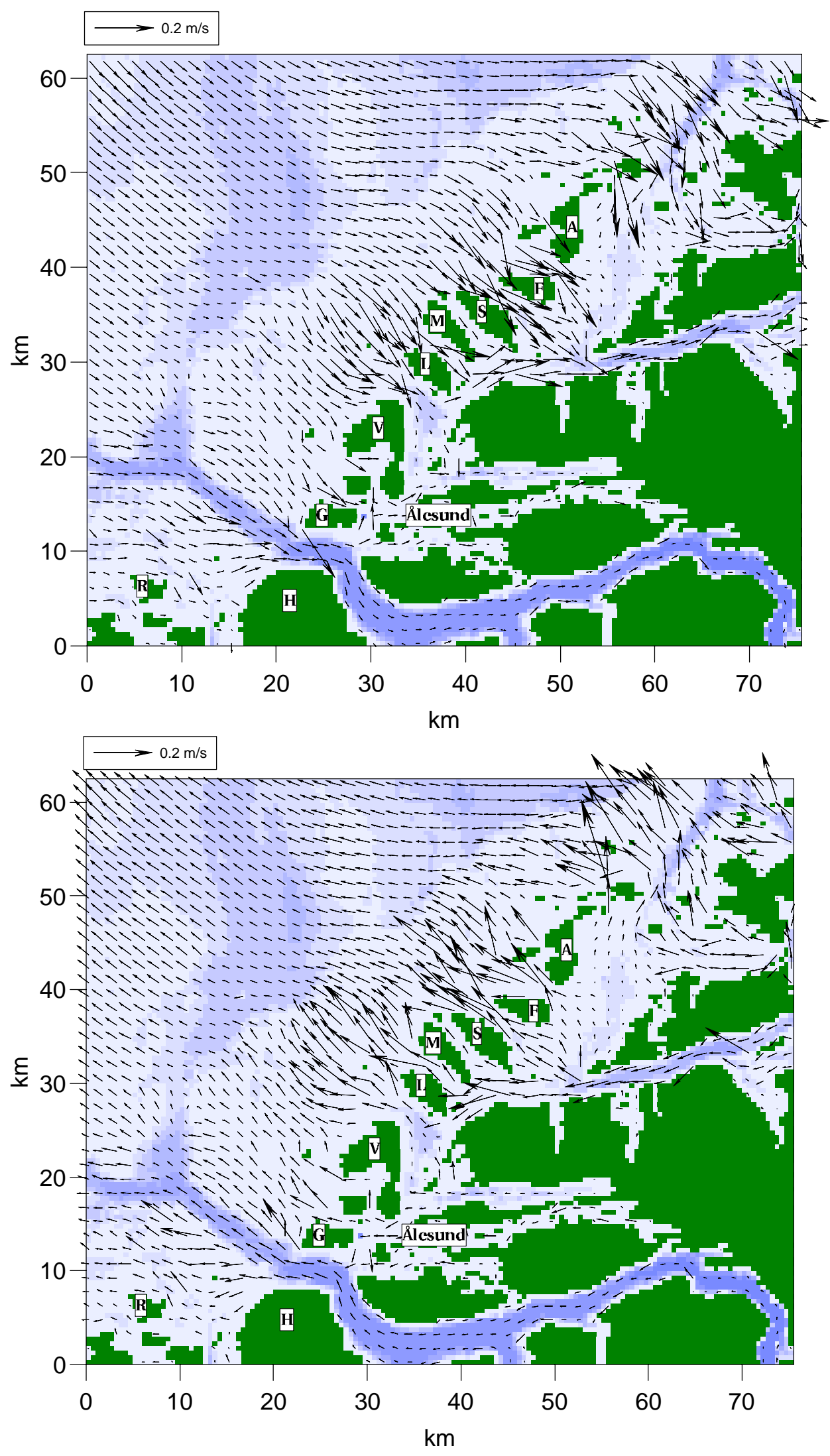

Figure 20: Upper panel: $M_{2}$ current field at the time of peak incoming current at the outer Sunnmøre area. Lower panel: $M_{2}$ current field at the time of peak outgoing current. Map codes as in figure 13, upper panel. 

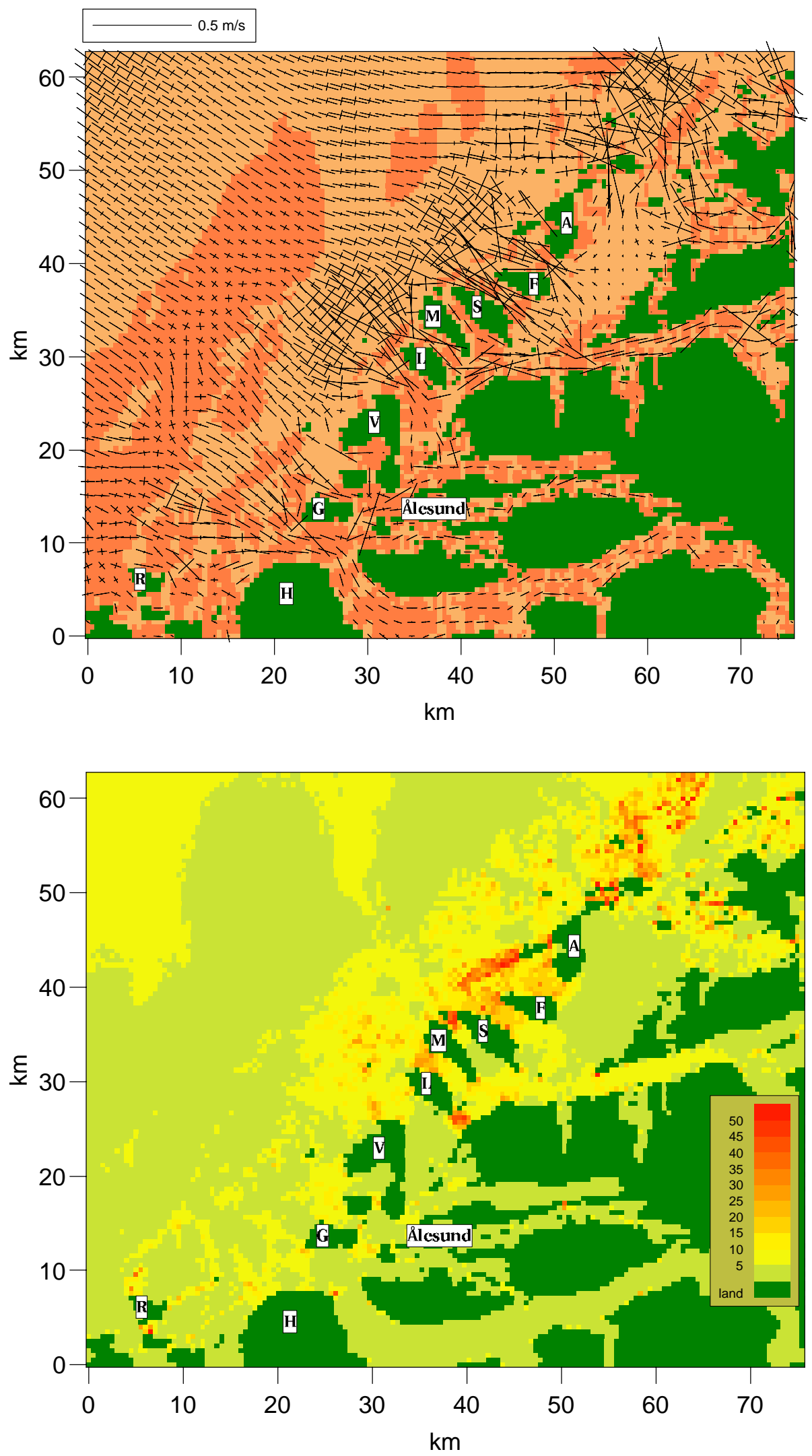

Figure 21: Upper panel: Tidal ellipse and rotation of the $M_{2}$ current vector. Bright shadowing clockwise rotation, darker shadowing counterclockwise at the outer Sunnmøre area. The crosses show the major and minor axis. Lower panel: Maximum $M_{2}$ current (major half axis). Color scale in $\mathrm{cm} / \mathrm{s}$, legend. Map codes as in figure 13, upper panel. 

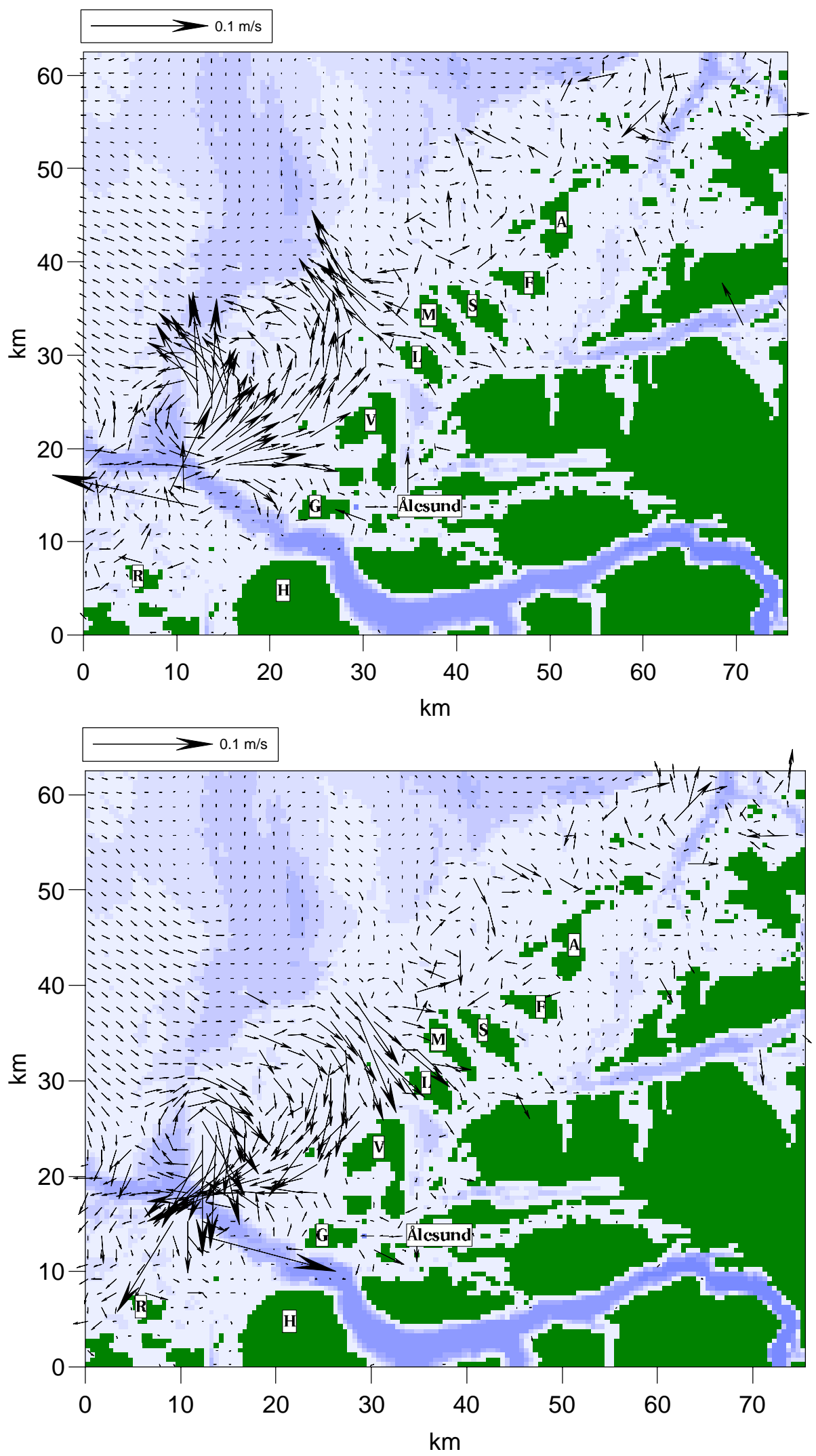

Figure 22: Upper panel: $K_{1}$ current field at the time of peak outgoing current at the outer Sunnmøre area. Lower panel: $K_{1}$ current field at the time of peak incoming current. Map codes as in figure 13, upper panel. 

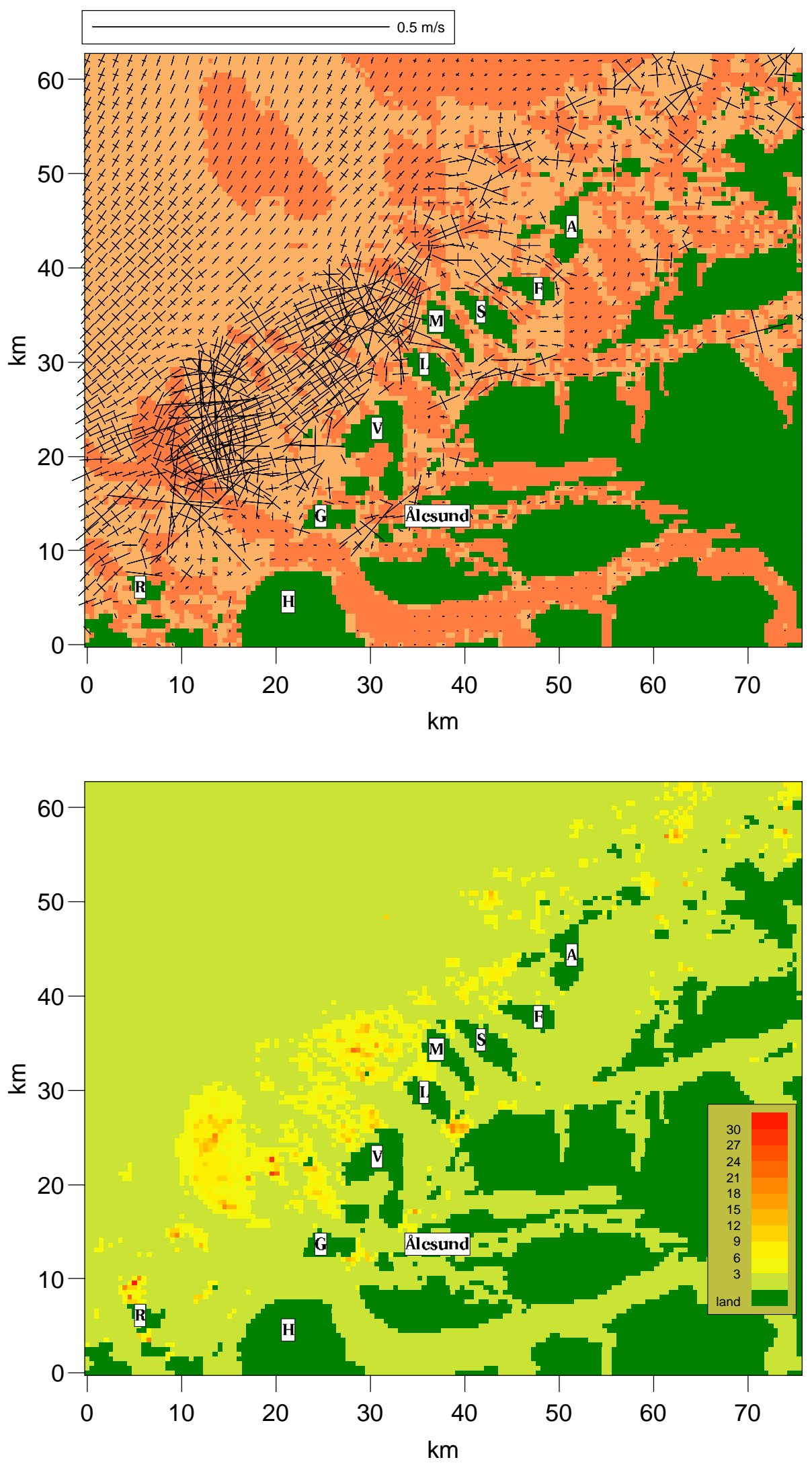

Figure 23: Upper panel: Tidal ellipse and rotation of the $K_{1}$ current vector. Bright shadowing clockwise rotation, darker shadowing counterclockwise at the outer Sunnmøre area. The crosses show the major and minor axis. Lower panel: Maximum $K_{1}$ current (major half axis). Color scale in $\mathrm{cm} / \mathrm{s}$, legend. Map codes as in figure 13, upper panel. 


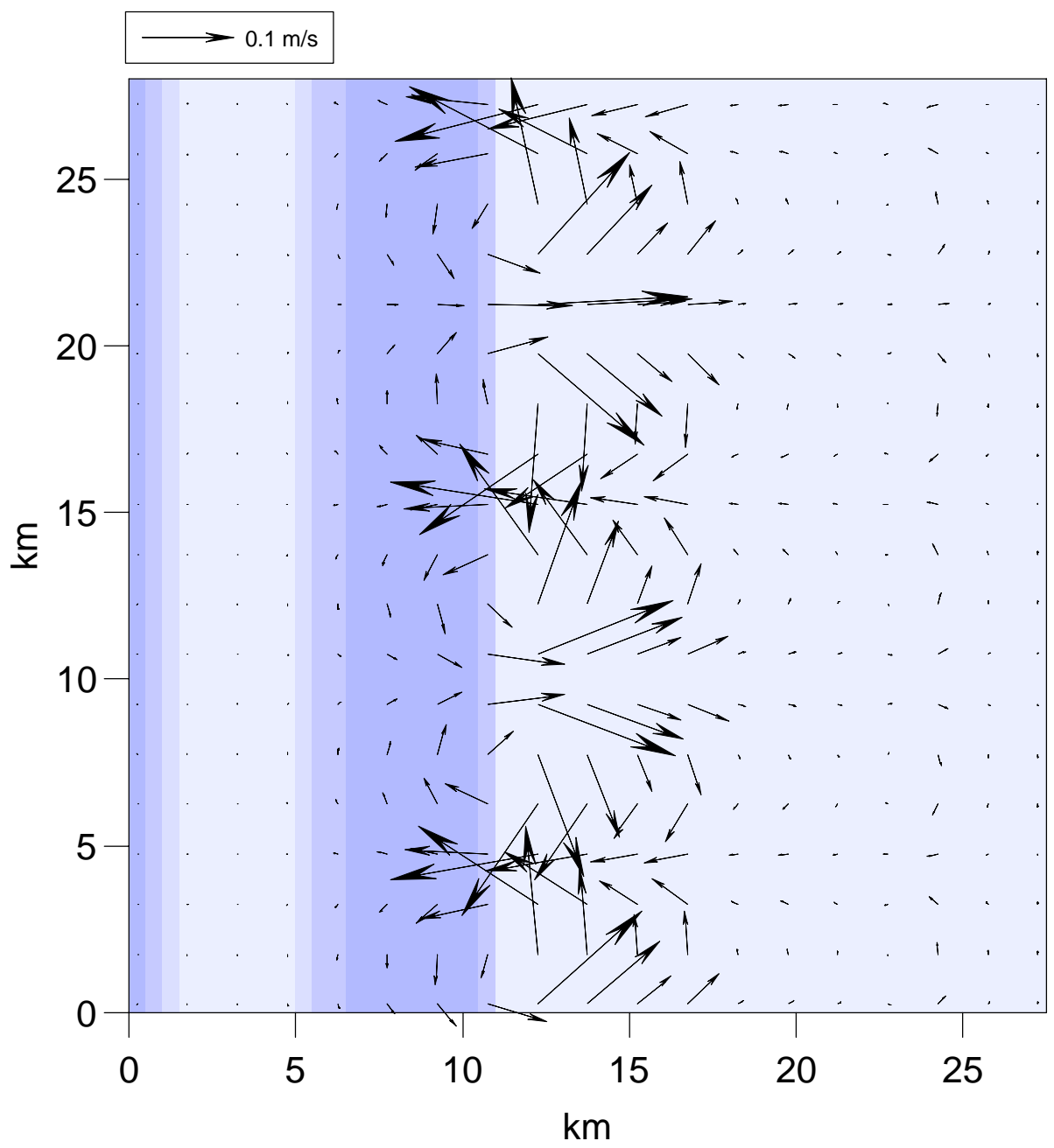

Figure 24: Current field for a 24 hours period shelf wave for a depth profile going from the western part of Vigra (map code $\mathrm{V}$ in figure 20) to the end of the plotting area in figure 20 . 


\section{Concluding remarks}

The high resolution depth integrated model is found to reveal important features of the dynamics of the tides outside the coast of Møre and Trøndelag. This large scale variation in sea level amplitude and phase for the three semi-diurnal constituents $M_{2}$, $S_{2}$, and $N_{2}$ is in good agreement with observations for most of the stations.

The simulations show that the diurnal tidal current dominates in some of the shallow areas outside the coast of Sunnmøre and likewise in some of the shallow areas further north. This unexpected result is as far as we know not revealed by any measurements.

Although the agreement between model and observation is generally very good systematic deviations, specially for the diurnal component, are seen. As indicated by our simple test for the $K_{1}$ component, this can be improved by the use of optimalization techniques.

The ability of the model to predict the current along the pipeline to Tjeldbergodden shows that the local tidal conditions are to a large extent determined by the large scale dynamics of the tide in deep water where non-linear effects are negligible. In order to simulate the current field in channels with strong tidal current turbulence, flow separation and eddy formation need to be represented in a more realistic way in the model. This will require use of adaptive grid or nesting of finer grid models in certain areas. Also, particularly at certain times of the year, density stratification may have a considerable effect on the tidal current and therefore needs to be incorporated in the model in order to provide accurate prediction of currents.

Despite these limitations the results of the simulations with this barotropic tidal model stand by their own right and could serve as a starting point for more advanced modelling exercises and as a guidance for future measurement programs.

\section{Acknowledgement}

The first version of this model with the high resolution matrix was developed and tested under a contract with Statoil which also has provided current and sea level data for model validation in this study.

We are grateful to the Norwegian Hydrographic Service for getting access to their data archive on sea level and current records. The assistance by O. Høvik and E. Dybesland in generating a high resolution depth matrix for the area is greatly appreciated. This work has also received support from The Research Council of Norway, contract 133102/431, BeMatA program. 


\section{References}

Davies, A. M., J. E. Jones, and J. Xing (1997a). Review of recent developments in tidal hydrodynamic modeling. I: Spectral models. Journal of Hydraulic Engineering 123(4), 278-292.

Davies, A. M., J. E. Jones, and J. Xing (1997b). Review of recent developments in tidal hydrodynamic modeling. II: Turbulence energy models. Journal of Hydraulic Engineering 123(4), 293-302.

Eide, L. I. (1979). Evidence of a topographically trapped vortex on the norwegian continental shelf. Deep Sea Res. 26/6A, 601-621.

Geyer, W. R. (1993). Three-dimensional tidal flow around headlands. Journal of Geophysical Research 98(1), 955-966.

Gjevik, B. (1990). Model simulations of tides and shelf waves along the shelves of the norwegian-greenland-barents seas. In A. M. Davies (Ed.), Modelling Marine Systems, Volume 1, pp. 187-219. CRC Press Inc.

Gjevik, B., O. Høvik, and H. Moe (1992). Simuering av tidevannet i kystområdet innenfor Haltenbanken. Report for Statoil.

Gjevik, B. and H. Moe (1994). Steady and transient flows around a bank located near a shelf edge. Contin. Shelf Res. 24, 1389-1409.

Gjevik, B., E. Nøst, and T. Straume (1990). Atlas of tides on the shelves of the Norwegian and the Barents seas. Report FoU-ST 90012, Department of Mathematics, University of Oslo.

Gjevik, B., E. Nøst, and T. Straume (1994). Model simulations of the tides in the Barents sea. Journal of Geophysical Research 99(C2), 3337-3350.

Gjevik, B. and T. Straume (1989). Simulations of the $M_{2}$ and the $K_{1}$ tide in the Nordic Seas and the Artic Ocean. Tellus A(41), 73-96.

Haugan, P. M., G. Evensen, J. A. Johannessen, O. M. Johannessen, and L. H. Pettersson (1991). Modelled and observed mesoscale circulation and wave-current refraction during the 1988 Norwegian continental shelf experiment. Journal of Geophysical Research 96(C6), 10487-10506.

Maddock, L. and R. D. Pingree (1978). Numerical simulation of the Portland tidal eddies. Estuarine and Coastal Marine Science 6, 353-363.

Martinsen, E. A. and H. Engedahl (1987). Implementation and Testing of a Lateral Boundary Scheme as an Open Boundary Condition in a Barotropic Ocean Model. Costal Engineering 11, 603-627.

Martinsen, E. A., B. Gjevik, and L. P. Røed (1979). A numerical model for long barotropic waves and storm surges along the western coast of Norway. Journal of Physical Oceanography 9(6), 1126-1138.

Mathisen, J.-P. (1998). Deep water current measurements. Final report. Report OCN R-98007, Oceanor, Trondheim, Norway.

Mathisen, J.-P., J. Arff, and Ø. Stokland (1997). Vurdering av miljøkonsekvensene som følge av bruforbindelse over Frøyafjorden. Report OCN R-96046, Oceanor, Trondheim, Norway. 
Mesinger, F. and A. Arakawa (1976). Numerical methods used in atmospheric models. In GARP Publ. Ser. WMO 17.

Moe, H., A. Ommundsen, and B. Gjevik (2000). A high resolution tidal model for the area around The Lofoten Islands, Northern Norway. Report, Department of Mathematics, University of Oslo, Oslo, Norway.

Norwegian Hydrographic Service (1992). OKN-Thematic map offshore Mid-Norway. Stavavger, Norway: Norwegian Hydrographic Service.

Norwegian Hydrographic Service (2000). Tide tables for the Norwegian coast and Svalbard (63 ed.). Stavavger, Norway: Norwegian Hydrographic Service.

Nøst, E. (1988). Simulering av tidevann på haltenbanken. Master's thesis, University of Oslo. Master thesis in Mechanics.

Orvik, K. A. and M. Mork (1996). Atlantic water transport from long term current measurements in the Svinøy section. In ICES Annual Science Conference, Number CM 1996/O:8., Reykjavik, Iceland.

Orvik, K. A., O. Skagseth, P. Jaccard, and M. Mork (1999). Atlantic inflow to the Nordic Seas from long term current measurements in the Svinøy section. In ICES Annual Science Conference, Number CM 1999/L:29., Stockholm, Sweden.

Orvik, K. A., O. Skagseth, and M. Mork (1999). Atlantic inflow to the Norwegian Seas. Quantification of transport and hydrographic features based on long-term current measurements from April 1995 to October 1998 in combination with shipboard ADCP and SeaSoar-CTD observations in the Svinøy section. Manuscript submitted to Deep Sea Research.

Poulain, P.-M., A. Warn-Varnas, and P. P. Niiler (1996). Near-surface circulation of the Nordic Seas as measured by Lagrangian drifters. Journal of Geophysical Research 101(C8), 18237-18258.

Schlichting, H. (1979). Boundary layer theory. New York: McGraw-Hill Book Company.

Sætre, R. (1999). Features of the central Norwegian shelf circulation. Continental Shelf Research 19, 1809-1831. 